

\title{
ATTENUATION OF CISPLATIN-INDUCED EMETOGENESIS BY STANDARDIZED BACOPA MONNIERA EXTRACTS IN THE PIGEON: BEHAVIOVRAL AND NEUROCHEMICAL CORRELATIONS
}

\author{
Ihsan Ullah ${ }^{1,2}$, Fazal Subhan ${ }^{2 *}$, John A. Rudd ${ }^{3}$, , Khalid Rauf ${ }^{4}$ \\ Javaid Alam $^{1}$ and Muhammad Shahid ${ }^{1}$ Robert D. E. Sewell ${ }^{5}$
}

\footnotetext{
${ }^{1}$ Department of Pharmacy, University of Swabi, Swabi, Pakistan

${ }^{2}$ Department of Pharmacy, University of Peshawar, Peshawar, Pakistan

${ }^{3}$ School of Biomedical Sciences, Faculty of Medicine, The Chinese University of Hong Kong, Shatin, N.T., Hong Kong SAR, China

${ }^{4}$ Department of Pharmacy, COMSAT institute of information technology, Abbottabad, Pakistan

${ }^{5}$ Welsh School of Pharmacy, Cardiff University, Redwood Building, King Edward VII Ave., Cardiff, CF10 3NB, UK
}

Short title: Antiemetic activity of Bacopa monniera

Correspondence to Dr. Fazal Subhan, Department of Pharmacy, University of Peshawar, Pakistan

Email: fazal_subhan@upesh.edu.pk

Phone: $+92-91-9216750 \quad$ Fax: $+92-91-9218131$ 


\begin{abstract}
:
Nausea and vomiting are the most distressing and common side effects of cancer chemotherapy which often result in patient non-compliance. In the present study, standardized methanolic fractions of Bacopa monniera $(B M)$ were evaluated against cisplatin induced emesis in the pigeon in relation to their activity on central and intestinal neurotransmitter levels.
\end{abstract}

Cisplatin $(7.0 \mathrm{mg} / \mathrm{kg}$, i.v.) induced reproducible emesis without lethality in healthy pigeons. The methanolic (10-40 mg/kg), the bacoside rich $n$-butanolic fractions of B. monniera (5-20 $\mathrm{mg} / \mathrm{kg})$ as well as the antioxidant $N$-(2-Mercaptoprpionyl) glycine $(10 \mathrm{mg} / \mathrm{kg})$ attenuated cisplatin induced emesis by $66.3 \%(P<0.05), 71.6 \% \quad(P<0.001)$ and $76.5 \% \quad(P<0.001)$, respectively; where the standard antiemetic, metoclopramide $(30 \mathrm{mg} / \mathrm{kg})$, produced a $48.9 \%$ reduction $(P<0.01)$.

The methanolic and n-butanolic fractions of $\mathrm{B}$. monniera at all of the doses tested significantly reduced the serotonin concentration $(P<0.001)$ in the brain stem and intestine 3 $\mathrm{h}$ after cisplatin administration, while at the $18^{\text {th }}$ hour, $B$. monniera treatments attenuated not only the dopamine upsurge in the area postrema and brain stem $(P<0.05-0.001)$, but also the intestinal 5-HT concentration $(P<0.01-0.001)$. B. monniera treatments alone did not alter the basal neurotransmitters or their metabolites in the brain areas and intestine.

The prolonged suppressive effect of $B M$ treatments on the behavioral signs of cisplatininduced emesis, the subsequent supportive neural evidence and the safety and tolerability profile suggest that $B$. monniera methanolic and bacoside rich $n$-butanolic fractions might be a valuable adjunct in the treatment of emetogenic chemotherapy and this warrants further study in other models of emesis. 


\section{Introduction:}

Nausea and vomiting induced by chemotherapeutic agents like cisplatin are accepted as the most distressing adverse effects of cancer chemotherapy[1,2]. These side effects often result in poor patient compliance and if not satisfactorily controlled, can lead to refusal of treatment [3]. The older classes of antiemetics including antagonists at histamine, dopamine, and muscarinic receptors exhibit only modest effects against chemotherapy emetogenesis. In addition, these antiemetics also possess their own inherent assortment of unpleasant side effects [4].

The development of 5- $\mathrm{HT}_{3}$ receptor antagonists subsequently revolutionized the treatment of chemotherapy induced vomiting (CIV), and interestingly, an acute (day 1) and delayed (post day 1) biphasic nature of their activities has been perceived. Unfortunately, approximately 10 - 30\% of patients are unprotected by $5-\mathrm{HT}_{3}$ receptor antagonists [5], the delayed phase of vomiting being the most poorly controlled [6]. Tachykinin $\mathrm{NK}_{1}$ receptor antagonists, such as aprepitant, have a wider spectrum of antiemetic action than the older classes of drugs, are now being used in combination with $5-\mathrm{HT}_{3}$ receptor antagonists and co-administered with glucocorticoids to control emetogenic chemotherapy [7].

Cancer chemotherapy is inevitably damaging to tissues, inducing lipid peroxidation and the generation of free radicals such as hydrogen peroxide, hydroxyl- and superoxide-anions $[8,9]$. In this regard, there are reports demonstrating the involvement of free radicals in the mediation of cisplatin induced vomiting [10,11]. Generation of free radicals is believed to occur at an early stage of treatment, and it is hypothesized to initiate the release of 5-HT from enterochromaffin cells in the gastrointestinal tract. The subsequent local activation of 5-HT receptors on abdominal vagal afferents is then thought to make a substantial contribution to the mechanism(s) giving raise to CIV 12,13]. Apart from serotonergic receptors $[12,14,15]$, 
tachykinin [16,17], cannabinoid [18] and DA receptors [19-21] have also attracted interest as targets for antiemetic efficacy and it is likely that they all play some role in the central control of chemotherapy emetogenesis $[18,19,22]$. DA $\mathrm{D}_{2}$ receptors, localized in the limbic system, hypothalamus, amygdala and also in the brain stem emetic circuitry have received particular attention in this respect [23].

The incapacity of any single antiemetic agent to provide universal efficacious control of chemotherapy induced emesis is guiding current research endeavor towards a more wideranging mechanistic approach. Indeed, there is evidence for the involvement of several neurotransmitter systems including serotonergic [24,25], dopaminergic [20,21] and neurokininergic $[16,26]$ pathways in emetic neuronal circuitry. In light of this, emesis induced by anticancer drugs is associated with elevated 5-HT levels in the intestinal mucosa as well as the brainstem $[27,28]$ and this is the reason why this neurotransmitter has been considered as one of the primary instigators of chemotherapy induced vomiting for quite some time [29]. This concept is additionally supported by human and animal studies demonstrating increased urinary levels of 5-HIAA [30,31] and 5-HT in intestinal ileal segments.

Bacopa monniera (Linn.) Pennell [syn Bacopa monniera (L) Wettst., Herpestis monniera, Gratiola monniera) (family - Scrophulariaceae), known as "Brahmi" in India and "Jal Neem Booti" in Pakistan is a perennial herb which is found in marshy places around the world including Pakistan[32]. $B M$ has a long history of clinical usage in ayurvedic medicine, particularly for the treatment of neuropathic diseases [33,34]. The herb has a number of identified pharmacological properties including an ability to block calcium channels [35], and to prevent DA receptor-mediated hyperactivity in rats [36]. $B M$ is also well-known to have antioxidant activity [37] and is protective against aluminum-induced oxidative stress, which is mechanistically similar to the oxidative stress induced by cisplatin [38-41]. 
In recent years, $B M$ has been studied in an attempt to identify its active constituents. Thus, bacoside "A" was shown to be the major constituent comprising a mixture of four compounds, namely bacoside $\mathrm{A}_{3}$ (Fig 1s) bacopaside II, (Fig 2s) bacosaponin C (Fig 2s), and jujubogenin isomer of bacosaponin C [42]. Since $B M$ possesses strong antioxidant activity, and inhibitory effects on hyperactivity mediated by DA receptors [43], we hypothesized that standardized extracts of the herb may have antiemetic properties. The present studies were designed, therefore, to investigate any antiemetic potential of the methanolic fraction of $B M$ (BM-MetFr), and the bacopaside rich n-butanolic fraction (BM-ButFr), against the cisplatininduced retching and vomiting paradigm in the pigeon. In conjunction with this work, concentrations of neurotransmitters and their metabolites were evaluated in the brain and intestine in order to expose any correlative changes with antiemetogenesis.

\section{Results:}

Cisplatin induced vomiting at doses as low as $5.0 \mathrm{mg} / \mathrm{kg}$, but the response was only seen in $60 \%$ of pigeons. Cisplatin $(7.0 \mathrm{mg} / \mathrm{kg})$ induced a response in all animals tested which comprised approximately 43 episodes following a mean latency of $\sim 67$ min (Figure 1A). Increasing the dose further augmented the number of vomiting episodes. Regardless of the dose, all responding animals appeared to vomit within the first two hours after cisplatin administration, with the most intense period occurring around the first hour (Figure 1B). There were no mortalities during $24 \mathrm{~h}$ of observation period. 
A: Dose-response relationship of cisplatin:

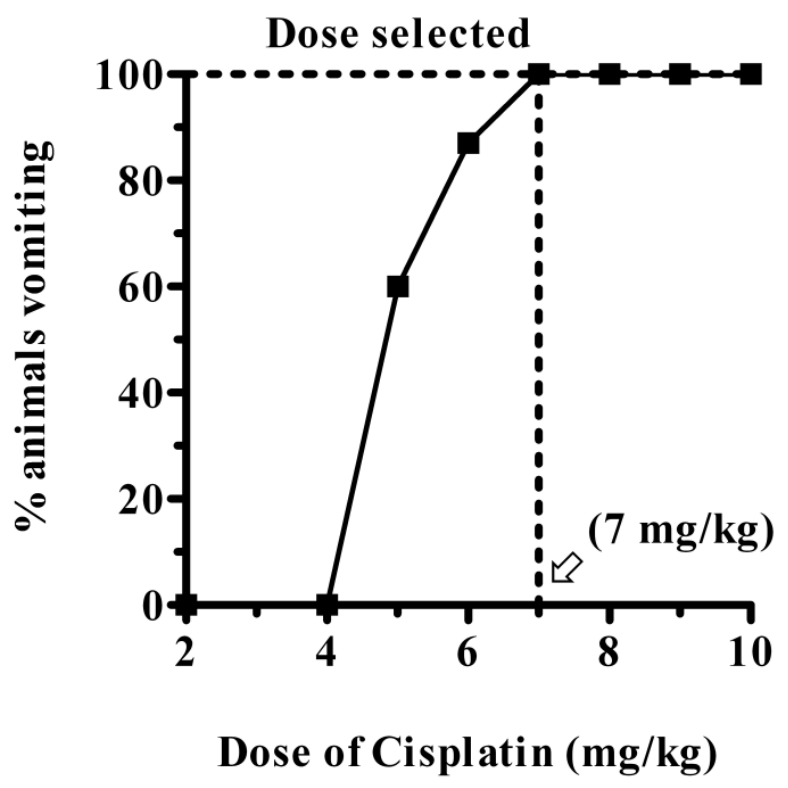

B. Time profile of cisplatin induced vomiting up to $24 \mathrm{hr}$ in the pigeon

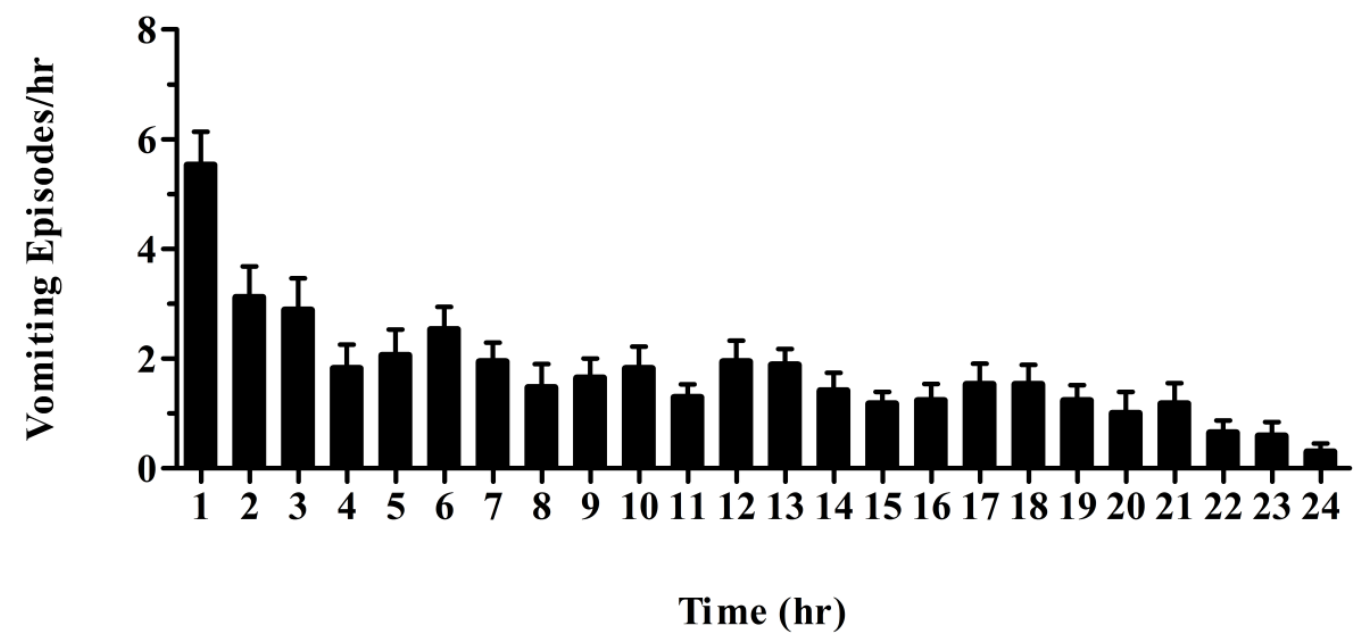

Figure 1. (A) Dose-response relationship for cisplatin $(2.0-10 \mathrm{mg} / \mathrm{kg})$ to induce vomiting in pigeons and (B) profile of cisplatin $(7.0 \mathrm{mg} / \mathrm{kg}$ i.v.) induced vomiting during a $24 \mathrm{hr}$ observation period. Data are represented by \pm s.e.m. $(n=17)$. 
A phytochemical investigation of crude BM-MetFr revealed the presence of saponins, flavonoids, tannins and triterpenoids, and the absence of alkaloids and glycosides (Table 1s).

Table 1(s). Phytochemical screening of BM-MetFr

\begin{tabular}{|c|c|c|c|}
\hline $\begin{array}{l}\text { Sample } \\
\text { No }\end{array}$ & Test & Observation & Result \\
\hline 1 & $\begin{array}{l}500 \mathrm{mg} \text { of } \mathrm{BM}-\mathrm{MetFr}+2 \mathrm{~mL} \text { acetic acid }+ \\
1 \mathrm{drop} \mathrm{FeCl} 3+1 \mathrm{~mL} \mathrm{H} 2 \mathrm{SO} 4\end{array}$ & $\begin{array}{l}\text { Absence of brown ring } \\
\text { color at interphase }\end{array}$ & Glycosides absent \\
\hline 2 & $\begin{array}{l}500 \mathrm{mg} \text { BM-MetFr }+5 \mathrm{~mL} \text { chloroform } \rightarrow \text { mixed } \\
\text { for } 5 \text { minutes } \rightarrow 10 \% \text { ammonia solution was added }\end{array}$ & $\begin{array}{l}\text { Absence of light green } \\
\text { color in upper ammonia } \\
\text { layer }\end{array}$ & Glycosides absent \\
\hline 3 & $\begin{array}{l}300 \mathrm{mg} \mathrm{BM}-\mathrm{MetFr}+5 \mathrm{~mL} \text { chloroform } \rightarrow \text { warmed } \\
\text { for } 30 \text { minutes } \rightarrow \text { sulphuric acid was added }\end{array}$ & $\begin{array}{l}\text { Dark red color in lower } \\
\text { layer }\end{array}$ & $\begin{array}{l}\text { Triterpenoids } \\
\text { present }\end{array}$ \\
\hline 4 & $\begin{array}{l}\text { Aqueous aliquot of BM-MetFr }+ \text { Ferric chloride } \\
\text { reagent }\end{array}$ & Green black color & Tannins present \\
\hline 5 & $\begin{array}{l}0.1 \mathrm{~g} \text { of } \mathrm{BM}-\mathrm{MetFr}+10 \mathrm{~mL} \text { distilled water } \rightarrow \\
\text { Filtered } \rightarrow 1 \mathrm{~mL} \text { filtrate }+ \text { ferric chloride reagent }\end{array}$ & Green black color & Tannins present \\
\hline 6 & $\begin{array}{l}100 \mathrm{mg} \mathrm{BM}-\mathrm{MetFr}+5 \mathrm{~mL} \text { ethanol } \rightarrow \text { Filter } \rightarrow 1 \\
\mathrm{~mL} \text { filtrate }+0.5 \mathrm{~N} \mathrm{KOH}\end{array}$ & Yellowish color & Flavonoids present \\
\hline 7 & $\begin{array}{l}300 \mathrm{mg} \mathrm{BM}-\mathrm{MetFr}+5 \mathrm{~mL} \text { Distilled water } \rightarrow \text { boil } \\
\text { for } 2 \text { minutes and cool } \rightarrow \text { vigorous shaking }\end{array}$ & $2.5 \mathrm{~cm}$ (froth length) & Saponins present \\
\hline 8 & $\begin{array}{l}0.2 \mathrm{mg} \mathrm{BM}-\mathrm{MetFr}+5 \mathrm{~mL} \text { normal saline } \rightarrow \\
\text { filtration } \rightarrow 1 \mathrm{~mL} \text { filtrate }+4 \mathrm{~mL} \text { of blood } \rightarrow \\
\text { centrifuge for } 5 \text { minutes }\end{array}$ & Severe hemolysis & Saponins present \\
\hline 9 & $\begin{array}{l}0.3 \text { g semisolid BM-MetFr }+2 \mathrm{M} \mathrm{HCl}+\text { Amyl } \\
\text { alcohol } \rightarrow \text { examine the alcoholic layer }\end{array}$ & No pink color & Alkaloids absent \\
\hline 10 & $\begin{array}{l}0.1 \mathrm{~g} \text { Semisolid BM-MetFr }+10 \% \mathrm{HCl} \rightarrow \text { filtration } \\
\rightarrow 1 \mathrm{~mL} \text { filtrate }+ \text { dragendorff's reagent }\end{array}$ & No ppt or turbidity & Alkaloids absent \\
\hline
\end{tabular}

HPLC - UV analysis of the $B M$ methanol fraction provided finger prints for the presence of bacoside " $\mathrm{A}$ " major components including bacoside $\mathrm{A}_{3}$, bacoside II and bacosaponin " $\mathrm{C}$ ". The total run time was 33 minutes at a flow rate of $0.6 \mathrm{~mL}$ using a wavelength of $205 \mathrm{~nm}$ (Figure 2). The peaks and retention times were first confirmed using standards of the respective bacosides. Our results indicated the presence of these bacosides in concentrations of $24 \pm 1.1 \mu \mathrm{g} / \mathrm{mg}, 4.76 \pm 0.03 \mu \mathrm{g} / \mathrm{mg}, 1.23 \pm 0.01 \mu \mathrm{g} / \mathrm{mg}(\mathrm{n}=3)$ for bacoside $\mathrm{A}_{3}$, bacoside II and bacosaponin $\mathrm{C}$, respectively. Likewise, the total concentration of bacoside "A" major components in BM-MetFr was $29.99 \pm 2.1 \mu \mathrm{g} / \mathrm{mg}$ of extract. 
HPLC analysis of the $B M$ n-butanol fraction revealed that it was the bacoside rich fraction which contained the bacoside "A" major components: bacoside $\mathrm{A}_{3}$, bacoside II and bacosaponin $\mathrm{C}$ in concentrations of $57.91 \pm 3.2 \mu \mathrm{g} / \mathrm{mg}, 40.60 \pm 0.9 \mu \mathrm{g} / \mathrm{mg}$, and $17.23 \pm 1.7$ $\mu \mathrm{g} / \mathrm{mg}(\mathrm{n}=3)$, respectively. Similarly, the total concentration of the three major components within bacoside "A" was $115.74 \pm 3.9 \mu \mathrm{g} / \mathrm{mg}$ in the n-butanol fraction or $38.37 \pm 0.7 \mu \mathrm{g} / \mathrm{gm}$ of the dry powder. These values closely correlated with the values reported previously by Rauf and others [44].

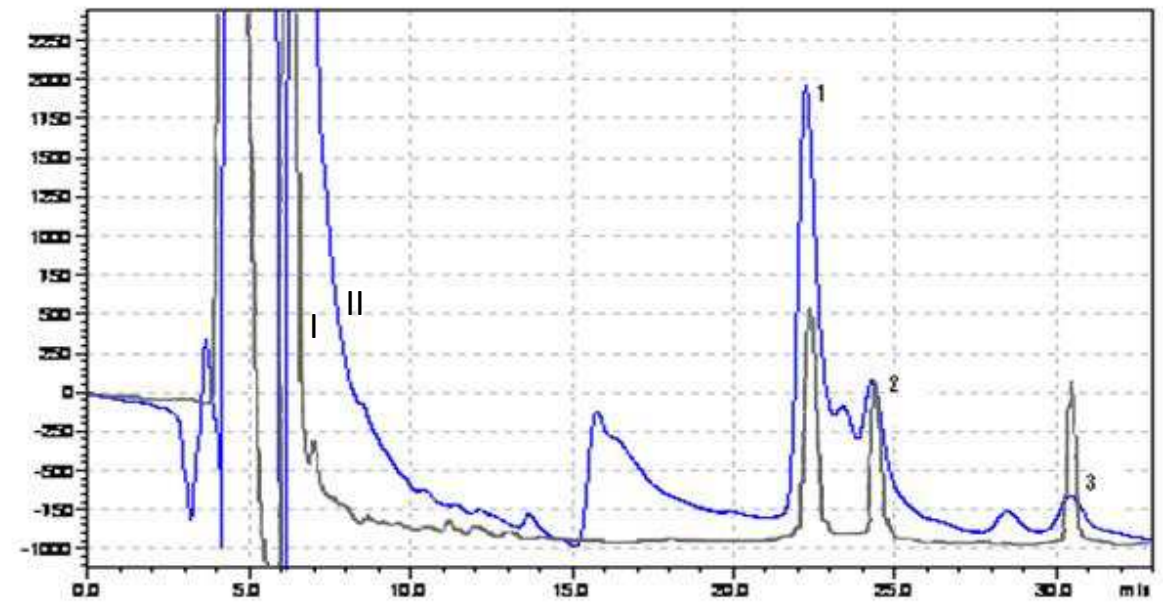

Figure 2. HPLC chromatogram showing peaks of bacoside " $\mathrm{A}$ " major components bacoside $\mathrm{A}_{3}$ (1), bacoside II (2) and bacosaponin C (3) of standard (I) BM-MrtFr (II) fractions.

In preliminary studies, cisplatin was selected at the dose of $7.0 \mathrm{mg} / \mathrm{kg}$ to evaluate the antiemetic potential of $B M$ fractions. In these experiments, cisplatin induced vomiting with a latency of $\sim 67 \mathrm{~min}$ and comprising a total of 43 episodes. The $B M$ methanolic fraction (10, 20 and $40 \mathrm{mg} / \mathrm{kg}$ ) dose dependently reduced cisplatin induced vomiting (Fig. 3), with the highest dose delaying the onset of vomiting by approximately 194 min and reducing the total number of episodes to $13.8 \pm 2.9(66.3 \%$ protection $)(P<0.05$; Table. 1$)$ during the $24 \mathrm{hr}$ observation period. The antiemetic action appeared to last for up to $16 \mathrm{hr}$ (Fig. $4 \mathrm{~B}$ ). 
Similarly, the $B M$ n-butanol fraction ( 5 - $20 \mathrm{mg} / \mathrm{kg}$ ) reduced cisplatin induced vomiting to 12 \pm 2.2 episodes ( $71.6 \%$ protection) and delayed the onset by approximately $67 \mathrm{~min}$. (Table 1 ) Moreover, the antiemetic action was evident for up to $24 \mathrm{hr}$ in animals treated with 5.0 and $10 \mathrm{mg} / \mathrm{kg}(P<0.001 ;$ Fig. $4 \mathrm{C})$. BM-ButFr $(10 \mathrm{mg})$ proved to be superior as it suppressed the response at least in one animal completely. MCP $(30 \mathrm{mg} / \mathrm{kg})$ delayed the onset of vomiting by $130 \mathrm{~min}$ and reduced vomiting during the $24 \mathrm{hr}$ observation period by $48.9 \%(P<0.001)$. Furthermore, unlike BM-MetFr and BM-ButFr, standard metoclopramide (MCP; $30 \mathrm{mg} / \mathrm{kg}$ ) was only found to be significantly effective to reduce vomiting during the first $8 \mathrm{hr}$ period (Fig. 4A).

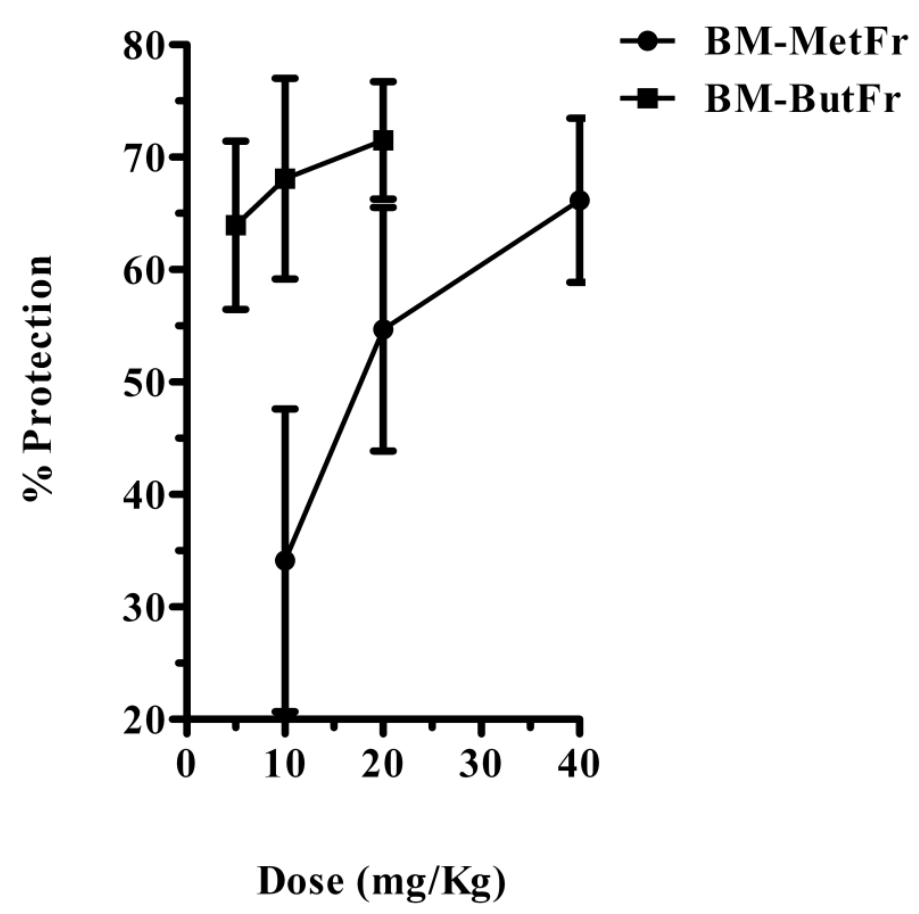

Figure 3. Dose response relationship of Bacopa monniera methanolic fraction (BM-MetFr) \& n-butanolic fraction (BM-ButFr) expressed as \% protection against cisplatin induced emesis in pigeons. Data represents the mean \pm s.e.m $(n=7-8)$. 
The antioxidant N-(2-Mercaptoprpionyl) glycine (MPG; $10 \mathrm{mg} / \mathrm{kg}$ ) attenuated cisplatin induced vomiting to $76.5 \%(P<0.001$, Table 12$)$ and delayed the onset of vomiting by 347 mins but the vomiting suppression was observed up to $12 \mathrm{~h}$ (Fig. $4 \mathrm{~A}$ ).

A. Vomiting suppression time profile of metoclopramide (MCP) and $\mathrm{N}$-(2-mercaptopropionyl) glycine (MPG) up to 24 hours.

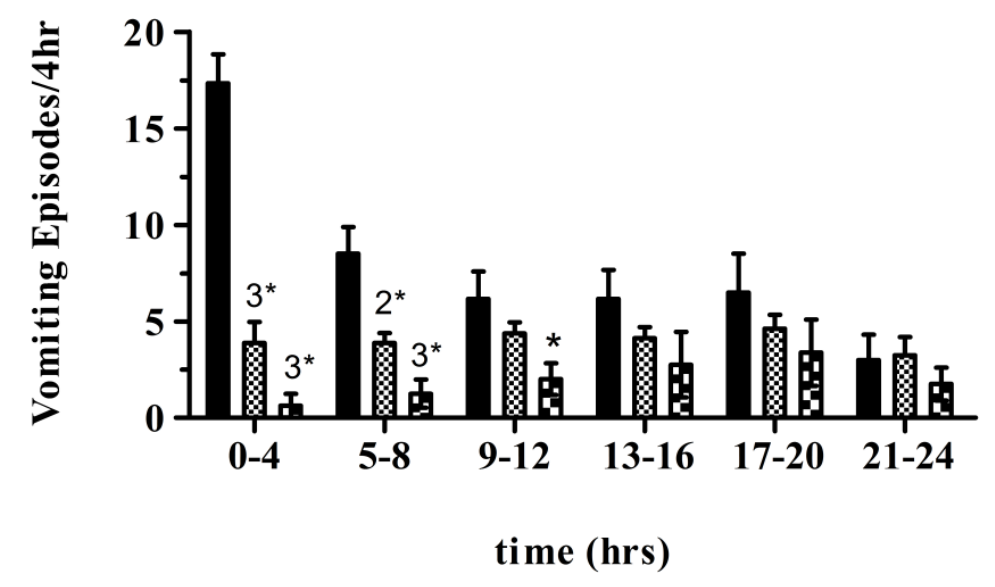

$\approx \mathrm{MCP}(30 \mathrm{mg} / \mathrm{kg})$

MPG $(10 \mathrm{mg} / \mathrm{kg})$

B. Vomiting suppression time profile of Bacopa monniera methanolic fraction (BM-MetFr up to 24 hours.

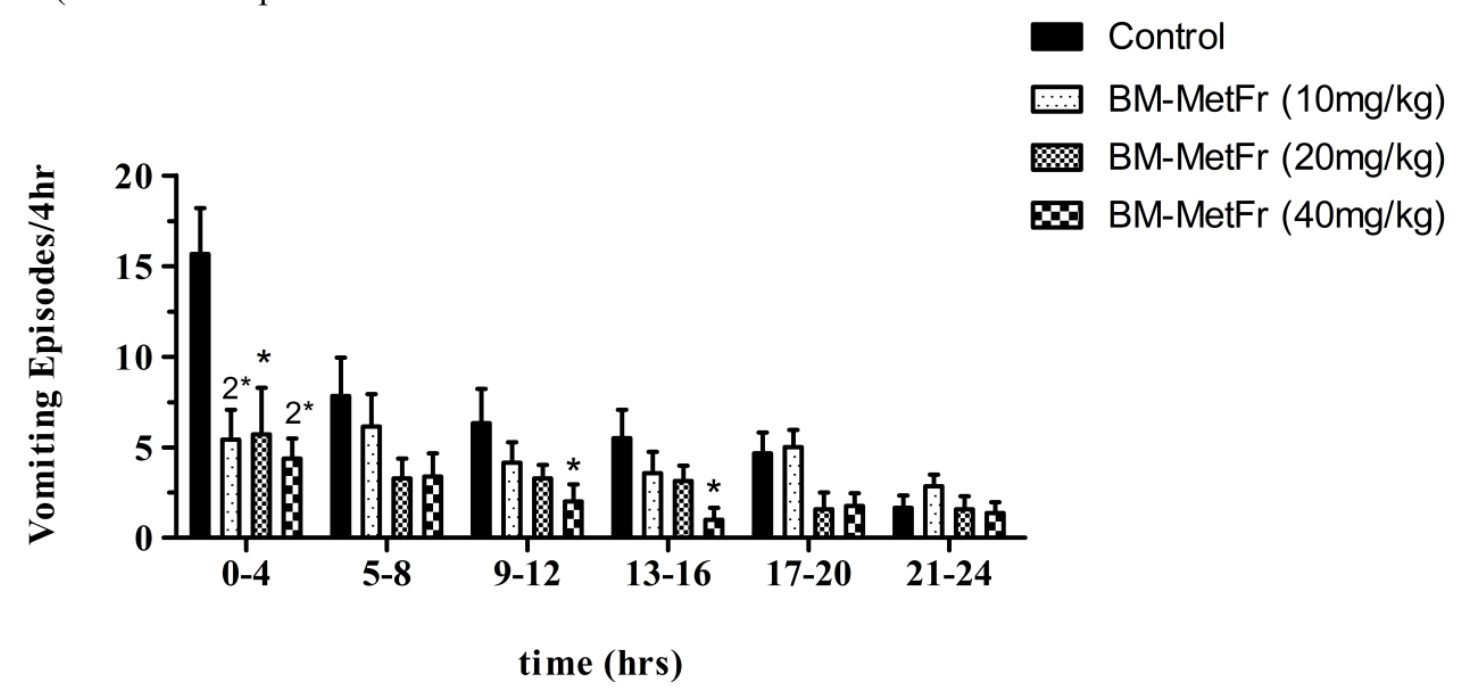


C. Vomiting suppression time profile of Bacopa monniera n-butanolic fraction (BM-But FR) up to 24 hours.

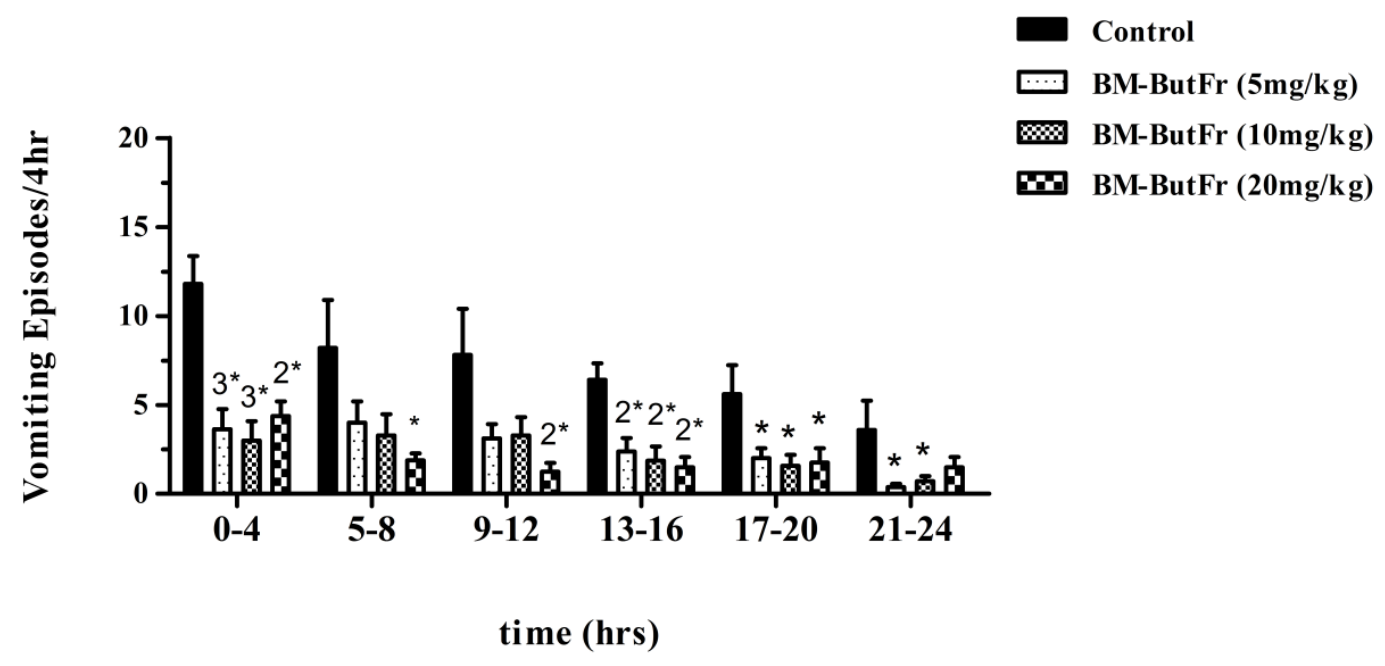

Figure 4. Vomiting suppression time profile in pigeons (A) standard metoclopramide (MCP; $30 \mathrm{mg} / \mathrm{kg}$ ) and N-(2-Mercaptoprpionyl) glycine (MPG; $10 \mathrm{mg} / \mathrm{kg}$ ) (B) Bacopa monniera methanolic fraction (BM-MetFr; 10, 20 and $40 \mathrm{mg} / \mathrm{kg}$ ) and (C) n-butanolic fraction (BMButFr; 5, 10 and $20 \mathrm{mg} / \mathrm{kg}$ ) against cisplatin-induced vomiting during a $24 \mathrm{hr}$ observation period; each bar represents the mean \pm s.e.m of vomiting episodes occurring during $4 \mathrm{hr}$ periods $(n=7-8)$. Values significantly different from cisplatin control are denoted as ${ }^{*} p<$ $0.05,{ }^{2} * p<0.01^{3 *} p<0.001$ (ANOVA followed by Tukey post hoc test). 
Table 1 Effect of BM-MetFr, BM-ButFr, MCP and MPG on cisplatin induced vomiting and jerking during a $24 \mathrm{hr}$ observation period in pigeons.

\begin{tabular}{|c|c|c|c|c|c|c|}
\hline Drug Treatment & Dose \& route & $\begin{array}{l}\text { Pigeons } \\
\text { n/ vomited }\end{array}$ & $\begin{array}{l}\mathbf{R}+\mathrm{V} \\
\text { Mean } \pm \text { sem }\end{array}$ & $\begin{array}{l}\text { Latency }(\mathrm{min}) \\
\text { Mean } \pm \text { sem }\end{array}$ & $\begin{array}{l}\text { Jerks } \\
\text { Mean } \pm \text { sem }\end{array}$ & $\begin{array}{l}\text { Wt loss }(\%) \\
\text { Mean } \pm \text { sem }\end{array}$ \\
\hline Saline + Cisplatin & $\begin{array}{l}02 \mathrm{ml} / \mathrm{kg} \text { i.m. + } \\
07 \mathrm{mg} / \mathrm{kg} \text { i.v }\end{array}$ & $6 / 6$ & $47 \pm 5.8$ & $74 \pm 6.3$ & $647 \pm 162$ & $15.3 \pm 1.4$ \\
\hline $\mathrm{MCP}+$ Cisplatin & $\begin{array}{l}30 \mathrm{mg} / \mathrm{kg} \text { i.m. + } \\
07 \mathrm{mg} / \mathrm{kg} \text { i.v }\end{array}$ & $8 / 8$ & $24 \pm 1.3 * *$ & $204 \pm 61.3$ & $351 \pm 21$ & $12.3 \pm 1.4$ \\
\hline MPG + Cisplatin & $\begin{array}{l}10 \mathrm{mg} / \mathrm{kg} \text { i.m. + } \\
07 \mathrm{mg} / \mathrm{kg} \text { i.v }\end{array}$ & $8 / 8$ & $11 \pm 5.6^{* * *}$ & $421 \pm 163$ & $225 \pm 109 *$ & $4.7 \pm 1.9^{* *}$ \\
\hline Saline + Cisplatin & $\begin{array}{l}02 \mathrm{ml} / \mathrm{kg} \text { i.m. } \\
+7 \mathrm{mg} / \mathrm{kg} \text { iv }\end{array}$ & $6 / 6$ & $41 \pm 5.2$ & $70 \pm 6.9$ & $614 \pm 115$ & $12 \pm 2$ \\
\hline \multirow{3}{*}{$\begin{array}{l}\text { BM-MetFr + } \\
\text { Cisplatin }\end{array}$} & $\begin{array}{l}10 \mathrm{mg} / \mathrm{kg} \text { i.m. + } \\
7 \mathrm{mg} / \mathrm{kg} \text { iv }\end{array}$ & $7 / 7$ & $27 \pm 5.6$ & $270 \pm 136$ & $610 \pm 161$ & $9.1 \pm 1.7$ \\
\hline & $\begin{array}{l}20 \mathrm{mg} / \mathrm{kg} \text { i.m. }+ \\
7 \mathrm{mg} / \mathrm{kg} \text { iv }\end{array}$ & & $18 \pm 4.4^{*}$ & $156 \pm 42$ & $405 \pm 167$ & $10.2 \pm 1.6$ \\
\hline & $\begin{array}{l}40 \mathrm{mg} / \mathrm{kg} \text { i.m. + } \\
7 \mathrm{mg} / \mathrm{kg} \text { iv }\end{array}$ & $8 / 8$ & $13 \pm 2.9^{*}$ & $264 \pm 132$ & $268 \pm 108$ & $8.9 \pm 1.7$ \\
\hline Saline + Cisplatin & $\begin{array}{l}02 \mathrm{ml} / \mathrm{kg} \text { i.m. + } \\
7 \mathrm{mg} / \mathrm{kg} \text { iv }\end{array}$ & $5 / 5$ & $43 \pm 5.8$ & $59 \pm 5.3$ & $509 \pm 67$ & $16.8 \pm 2$ \\
\hline \multirow{3}{*}{$\begin{array}{l}\text { BM-ButFr + } \\
\text { Cisplatin }\end{array}$} & $\begin{array}{l}5 \mathrm{mg} / \mathrm{kg} \text { i.m. + } \\
7 \mathrm{mg} / \mathrm{kg} \text { iv }\end{array}$ & & $15 \pm 3.2 * * *$ & $152 \pm 35$ & $309 \pm 83$ & $8.3 \pm 1.6^{*}$ \\
\hline & $\begin{array}{l}10 \mathrm{mg} / \mathrm{kg} \text { i.m. + } \\
7 \mathrm{mg} / \mathrm{kg} \text { iv }\end{array}$ & & $13 \pm 3.8 * * *$ & $142 \pm 46$ & $326 \pm 137$ & $5.2 \pm 1 * * *$ \\
\hline & $\begin{array}{l}20 \mathrm{mg} / \mathrm{kg} \text { i.m. + } \\
7 \mathrm{mg} / \mathrm{kg} \text { iv }\end{array}$ & $8 / 8$ & $12 \pm 2.2 * * *$ & $126 \pm 14.9$ & $185 \pm 38$ & $5.6 \pm 1.6 * * *$ \\
\hline
\end{tabular}

$* P<0.05, * * P<0.01 * * * P<0.001$ as compared to cisplatin control (ANOVA followed by

Tukey post hoc test).

Control cisplatin treated animals lost $\sim 14.7 \%$ of their starting body weight while, animals treated with BM-ButFr $(5,10$ and $20 \mathrm{mg} / \mathrm{kg})$ as well as MPG $(10 \mathrm{mg} / \mathrm{kg})$ lost less than $9 \%$ of their starting body weight. These differences compared to the cisplatin control group were found to be statistically significant $(P<0.05-0.001$, Table 1$)$. In the control cisplatin treated animals, there were $\sim 590$ jerking episodes during the $24 \mathrm{hr}$ observation period. Neither fraction of $B M$ at those doses studied evoked any effect on any jerking episodes although MPG did significantly reduce cisplatin induced jerks $(P<0.05$, Table. 2$)$.

As shown in table 2, neither BM-MetFr (10, 20 and $40 \mathrm{mg} / \mathrm{kg})$ nor BM-ButFr $(5.0,10$ and 20 $\mathrm{mg} / \mathrm{kg}$ ) significantly modified basal levels of the neurotransmitters (NA, DA and 5-HT) or 
their metabolites (DOPAC, HVA and 5-HIAA) in the area postrema and brain stem or the small intestine. However, both BM-MetFr (10, 20 and $40 \mathrm{mg} / \mathrm{kg})$ and BM-ButFr $(10 \mathrm{mg} / \mathrm{kg})$ significantly decreased $(P<0.01)$ the level of 5-HIAA in the brain stem. Moreover, intestinal NA showed an upsurge $(P<0.001)$ in response to BM-ButFr $(20 \mathrm{mg} / \mathrm{kg})($ Table 2$)$.

Table 2 Effect of metoclopramide (MCP), $B M$ methanolic fraction (BM-MetFr) or $\mathrm{n}$ butanolic fraction (BM-ButFr) on basal level of neurotransmitters (ng/mg tissue wet weight) and their metabolites in brain areas and the small intestine of pigeons:

\begin{tabular}{|c|c|c|c|c|c|c|}
\hline Treatment & NA & $\overline{\text { DOPAC }}$ & DA & 5HIAA & HVA & 5HT \\
\hline \multicolumn{7}{|c|}{ Area postrema } \\
\hline Saline & $0.610 \pm 0.014$ & $0.382 \pm 0.111$ & $0.590 \pm 0.146$ & $0.158 \pm 0.036$ & $0.913 \pm 0.095$ & $0.062 \pm 0.034$ \\
\hline MCP 30mg & $0.023 \pm 0.005$ & $0.017 \pm 0.006$ & $0.025 \pm 0.012$ & $0.005 \pm 0.001 *$ & $0.121 \pm 0.063 *$ & $0.023 \pm 0.001$ \\
\hline BM-MetFr 10mg & $0.058 \pm 0.017$ & $0.047 \pm 0.010$ & $0.070 \pm 0.007$ & $0.017 \pm 0.002$ & $0.346 \pm 0.047$ & $0.014 \pm 0.002$ \\
\hline BM-MetFr 20mg & $0.106 \pm 0.039$ & $0.168 \pm 0.074$ & $0.186 \pm 0.066$ & $0.050 \pm 0.025$ & $0.238 \pm 0.117$ & $0.054 \pm 0.034$ \\
\hline BM-MetFr 40mg & $0.336 \pm 0.174$ & $0.092 \pm 0.025$ & $0.216 \pm 0.089$ & $0.032 \pm 0.011$ & $0.476 \pm 0.151$ & $0.035 \pm 0.014$ \\
\hline BM-ButFr 05mg & $0.261 \pm 0.031$ & $0.043 \pm 0.010$ & $0.044 \pm 0.105$ & $0.207 \pm 0.041$ & $0.426 \pm 0.072$ & $0.146 \pm 0.050$ \\
\hline BM-ButFr 10mg & $0.044 \pm 0.023$ & $0.115 \pm 0.034$ & $0.277 \pm 0.054$ & $0.047 \pm 0.006$ & $0.356 \pm 0.098$ & $0.020 \pm 0.004$ \\
\hline BM-ButFr 20mg & $0.909 \pm 0.165$ & $0.313 \pm 0.087$ & $0.802 \pm 0.210$ & $0.066 \pm 0.028$ & $0.854 \pm 0.440$ & $0.105 \pm 0.057$ \\
\hline \multicolumn{7}{|c|}{ Brain stem } \\
\hline Saline & $0.094 \pm 0.022$ & $0.060 \pm 0.020$ & $0.175 \pm 0.078$ & $0.060 \pm 0.021$ & $0.060 \pm 0.016$ & $0.010 \pm 0.003$ \\
\hline MCP 30mg & $0.119 \pm 0.033$ & $0.027 \pm 0.006$ & $0.044 \pm 0.012$ & $0.007 \pm 0.001 * * *$ & $0.066 \pm 0.031$ & $0.019 \pm 0.002$ \\
\hline BM-MetFr 10mg & $0.040 \pm 0.020$ & $0.017 \pm 0.006$ & $0.063 \pm 0.027$ & $0.011 \pm 0.003 * *$ & $0.051 \pm 0.025$ & $0.037 \pm 0.019$ \\
\hline BM-MetFr 20mg & $0.147 \pm 0.091$ & $0.052 \pm 0.036$ & $0.058 \pm 0.040$ & $0.005 \pm 0.001 * *$ & $0.037 \pm 0.021$ & $0.019 \pm 0.005$ \\
\hline BM-MetFr 40mg & $0.020 \pm 0.009$ & $0.035 \pm 0.002$ & $0.022 \pm 0.018$ & $0.003 \pm 0.001 * * *$ & $0.022 \pm 0.015$ & $0.010 \pm 0.002$ \\
\hline BM-ButFr 05mg & $0.108 \pm 0.010$ & $0.015 \pm 0.001$ & $0.698 \pm 0.407$ & $0.067 \pm 0.014$ & $0.021 \pm 0.003$ & $0.167 \pm 0.014 * * *$ \\
\hline BM-ButFr 10mg & $0.054 \pm 0.016$ & $0.021 \pm 0.006$ & $0.046 \pm 0.011$ & $0.011 \pm 0.001 * *$ & $0.032 \pm 0.022$ & $0.011 \pm 0.002$ \\
\hline BM-ButFr 20mg & $0.156 \pm 0.097$ & $0.084 \pm 0.050$ & $0.178 \pm 0.110$ & $0.031 \pm 0.001$ & $0.243 \pm 0.077^{* * *}$ & $0.041 \pm 0.005$ \\
\hline \multicolumn{7}{|c|}{ Intestine } \\
\hline Saline & $0.194 \pm 0.059$ & $0.067 \pm 0.020$ & $0.090 \pm 0.064$ & $0.076 \pm 0.058$ & $0.056 \pm 0.025$ & $0.049 \pm 0.016$ \\
\hline MCP 30mg & $0.138 \pm 0.039$ & $0.054 \pm 0.025$ & $0.059 \pm 0.018$ & $0.097 \pm 0.022$ & $0.198 \pm 0.102$ & $0.062 \pm 0.013$ \\
\hline BM-MetFr 10mg & $0.117 \pm 0.047$ & $0.106 \pm 0.047$ & $0.089 \pm 0.045$ & $0.061 \pm 0.016$ & $0.069 \pm 0.032$ & $0.236 \pm 0.103$ \\
\hline BM-MetFr 20mg & $0.114 \pm 0.040$ & $0.110 \pm 0.053$ & $0.329 \pm 0.125$ & $0.077 \pm 0.014$ & $0.032 \pm 0.012$ & $0.158 \pm 0.022$ \\
\hline
\end{tabular}




\begin{tabular}{|c|c|c|c|c|c|c|}
\hline BM-MetFr 40mg & $0.015 \pm 0.006$ & $0.026 \pm 0.003$ & $0.011 \pm 0.005$ & $0.028 \pm 0.004$ & $0.013 \pm 0.009$ & $0.044 \pm 0.007$ \\
\hline BM-ButFr 05mg & $0.204 \pm 0.033$ & $0.005 \pm 0.001$ & $0.123 \pm 0.052$ & $0.268 \pm 0.068 * *$ & $0.077 \pm 0.025$ & $0.848 \pm 0.187 * * *$ \\
\hline BM-ButFr 10mg & $0.290 \pm 0.083$ & $0.144 \pm 0.109$ & $0.289 \pm 0.196$ & $0.121 \pm 0.028$ & $0.247 \pm 0.107$ & $0.106 \pm 0.026$ \\
\hline BM-ButFr 20mg & $1.328 \pm 0.271^{* * *}$ & $0.090 \pm 0.044$ & $0.244 \pm 0.162$ & $0.051 \pm 0.014$ & $0.142 \pm 0.052$ & $0.145 \pm 0.036$ \\
\hline
\end{tabular}

$* P<0.05, * * P<0.01, * * * P<0.001$ as compared to cisplatin control (ANOVA followed by

Tukey post hoc analysis; $n=6-8)$.

Cisplatin treatment significantly increased $(P<0.001)$ the concentration of 5-hydroxy tryptamine (5-HT) in the brain stem and small intestine as compared to basal control levels, while no significant increase was observed in the area postrema (Table 3). Treatment with MCP $(30 \mathrm{mg} / \mathrm{kg})$ did not modify the concentrations of NA, DOPAC, DA, 5-HIAA and HVA in either brain area or the intestine, but it did significantly decrease $(P<0.001)$ the concentration of 5-HT in the brain stem and intestine as compared to the cisplatin control (Table 3). In addition to its inhibitory effects on 5-HT, MCP also decreased the 5-HIAA concentration in the area postrema (Table 4), while no significant change was observed in the brain stem or small intestine (Tables 3 and 4).

BM-MetFr (10, 20 and $40 \mathrm{mg} / \mathrm{kg})$ and BM-ButFr $(5.0,10$ and $20 \mathrm{mg} / \mathrm{kg})$ treatments reduced the concentration of 5HT in the brain stem $(P<0.001)$ and intestine $(P<0.001$, Table 3$)$ as compared to cisplatin control, without any significant effects on NA, DOPAC, HVA and 5HIAA. Furthermore, no significant alteration was observed in the area postrema. 
Table 3 Effect of standard metoclopramide (MCP), BM methanolic fraction (BM-MetFr) or n-butanolic fraction (BM-ButFr) on neurotransmitters (ng/mg tissue wet weight) and their metabolites in brain areas and small intestine 3 hours after cisplatin treatment in pigeons:

\begin{tabular}{|c|c|c|c|c|c|c|}
\hline Treatment & NA & DOPAC & $\mathbf{D A}$ & 5HIAA & HVA & 5HT \\
\hline & & & Area postrema & & & \\
\hline Saline & $0.571 \pm 0.072$ & $0.389 \pm 0.108$ & $0.543 \pm 0.130$ & $0.290 \pm 0.059$ & $1.374 \pm 0.485$ & $0.011 \pm 0.001$ \\
\hline Cisplatin & $1.411 \pm 1.160$ & $0.299 \pm 0.132$ & $0.073 \pm 0.023$ & $0.211 \pm 0.079$ & $3.859 \pm 3.373$ & $0.316 \pm 0.093$ \\
\hline $\mathrm{MCP} 30 \mathrm{mg}$ & $0.116 \pm 0.078$ & $0.106 \pm 0.040$ & $0.223 \pm 0.103$ & $0.024 \pm 0.005$ & $0.069 \pm 0.045$ & $0.023 \pm 0.005$ \\
\hline BM-MetFr 10mg & $0.537 \pm 0.144$ & $0.129 \pm 0.032$ & $0.245 \pm 0.066$ & $0.035 \pm 0.010$ & $1.301 \pm 0.515$ & $0.020 \pm 0.009$ \\
\hline BM-MetFr 20mg & $0.682 \pm 0.297$ & $0.358 \pm 0.222$ & $0.844 \pm 0.585$ & $0.109 \pm 0.061$ & $0.447 \pm 0.215$ & $0.042 \pm 0.009$ \\
\hline BM-MetFr 40mg & $0.250 \pm 0.082$ & $0.206 \pm 0.009$ & $0.699 \pm 0.143$ & $0.035 \pm 0.007$ & $0.393 \pm 0.092$ & $0.027 \pm 0.006$ \\
\hline BM-ButFr 05mg & $0.960 \pm 0.146$ & $0.492 \pm 0.088$ & $0.558 \pm 0.128$ & $0.238 \pm 0.039$ & $1.603 \pm 0.341$ & $1.990 \pm 1.646$ \\
\hline BM-ButFr 10mg & $0.445 \pm 0.098$ & $0.110 \pm 0.031$ & $0.197 \pm 0.058$ & $0.038 \pm 0.017$ & $0.319 \pm 0.217$ & $0.025 \pm 0.011$ \\
\hline \multirow[t]{2}{*}{ BM-ButFr 20mg } & $0.109 \pm 0.032$ & $0.058 \pm 0.012$ & $0.122 \pm 0.020$ & $0.025 \pm 0.006$ & $1.317 \pm 0.414$ & $0.020 \pm 0.003$ \\
\hline & & & Brain stem & & & \\
\hline Saline & $0.071 \pm 0.004$ & $0.073 \pm 0.012$ & $0.069 \pm 0.023$ & $0.017 \pm 0.015$ & $0.022 \pm 0.010$ & $0.031 \pm 0.002$ \\
\hline Cisplatin & $0.080 \pm 0.019$ & $0.130 \pm 0.098$ & $0.032 \pm 0.001$ & $0.049 \pm 0.013$ & $0.016 \pm 0.008$ & $0.138 \pm 0.018 \# \# \#$ \\
\hline $\mathrm{MCP} 30 \mathrm{mg}$ & $0.044 \pm 0.016$ & $0.015 \pm 0.005$ & $0.018 \pm 0.011$ & $0.041 \pm 0.001$ & $0.042 \pm 0.002$ & $0.021 \pm 0.001 * * *$ \\
\hline BM-MetFr 10mg & $0.152 \pm 0.050$ & $0.053 \pm 0.021$ & $0.011 \pm 0.025$ & $0.016 \pm 0.004$ & $0.102 \pm 0.028$ & $0.012 \pm 0.004 * * *$ \\
\hline BM-MetFr 20mg & $0.145 \pm 0.071$ & $0.057 \pm 0.021$ & $0.093 \pm 0.030$ & $0.025 \pm 0.005$ & $0.220 \pm 0.062$ & $0.007 \pm 0.001 * * *$ \\
\hline BM-MetFr 40mg & $0.132 \pm 0.007$ & $0.097 \pm 0.006$ & $0.797 \pm 0.086$ & $0.025 \pm 0.003$ & $0.222 \pm 0.128$ & $0.018 \pm 0.001 * * *$ \\
\hline BM-ButFr 05mg & $0.037 \pm 0.010$ & $0.013 \pm 0.001$ & $0.010 \pm 0.001$ & $0.021 \pm 0.004$ & $0.024 \pm 0.001$ & $0.090 \pm 0.020^{*}$ \\
\hline BM-ButFr 10mg & $0.068 \pm 0.011$ & $0.139 \pm 0.126$ & $0.052 \pm 0.040$ & $0.055 \pm 0.001$ & $0.215 \pm 0.077$ & $0.017 \pm 0.002 * * *$ \\
\hline \multirow[t]{2}{*}{ BM-ButFr 20mg } & $0.037 \pm 0.004$ & $0.083 \pm 0.014$ & $0.076 \pm 0.016$ & $0.018 \pm 0.001$ & $0.289 \pm 0.023$ & $0.006 \pm 0.001 * * *$ \\
\hline & & & Intestine & & & \\
\hline Saline & $0.374 \pm 0.184$ & $0.105 \pm 0.040$ & $0.137 \pm 0.054$ & $0.410 \pm 0.269$ & $0.054 \pm 0.022$ & $0.044 \pm 0.016$ \\
\hline Cisplatin & $0.208 \pm 0.032$ & $0.015 \pm 0.002$ & $0.002 \pm 0.000$ & $0.285 \pm 0.020$ & $0.035 \pm 0.003$ & $0.821 \pm 0.137 \# \# \#$ \\
\hline MCP 30mg & $0.119 \pm 0.044$ & $0.060 \pm 0.059$ & $0.164 \pm 0.127$ & $0.033 \pm 0.005$ & $0.086 \pm 0.030$ & $0.045 \pm 0.006 * * *$ \\
\hline BM-MetFr 10mg & $0.152 \pm 0.050$ & $0.053 \pm 0.021$ & $0.116 \pm 0.025$ & $0.016 \pm 0.004$ & $0.102 \pm 0.028$ & $0.012 \pm 0.004 * * *$ \\
\hline BM-MetFr 20mg & $0.229 \pm 0.116$ & $0.048 \pm 0.031$ & $0.066 \pm 0.044$ & $0.028 \pm 0.004$ & $0.348 \pm 0.185$ & $0.009 \pm 0.001^{* * *}$ \\
\hline BM-MetFr 40mg & $0.235 \pm 0.066$ & $0.101 \pm 0.036$ & $0.530 \pm 0.235$ & $0.082 \pm 0.010$ & $0.290 \pm 0.112$ & $0.048 \pm 0.021 * * *$ \\
\hline BM-ButFr 05mg & $0.051 \pm 0.024$ & $0.016 \pm 0.007$ & $0.040 \pm 0.023$ & $0.208 \pm 0.026$ & $0.040 \pm 0.026$ & $0.420 \pm 0.069 * * *$ \\
\hline BM-ButFr 10mg & $0.087 \pm 0.026$ & $0.024 \pm 0.013$ & $0.041 \pm 0.026$ & $0.021 \pm 0.008$ & $0.498 \pm 0.353$ & $0.005 \pm 0.002 * * *$ \\
\hline BM-ButFr 20mg & $0.238 \pm 0.036$ & $0.105 \pm 0.066$ & $0.112 \pm 0.035$ & $0.023 \pm 0.004$ & $0.784 \pm 0.291$ & $0.027 \pm 0.008 * * *$ \\
\hline
\end{tabular}


Neurotransmitter or metabolite levels significantly different from cisplatin control are denoted by $* P<0.05$, $* * * P<0.001$, while Values significantly different as from basal levels are denoted by \#\#\#P<0.001 (ANOVA followed by Tukey post hoc analysis; $\mathrm{n}=6-8$ ).

Cisplatin increased the level of DA highly significantly $(P<0.001)$ in the area postrema, while no significant increase was observed in the brain stem or small intestine (Table 45 ). Concentration levels of 5-HT were also raised in the brain stem $(P<0.05)$ and small intestine $(P<0.001)$, without affecting NA, DOPAC, 5-HIAA or HVA levels in the brain stem and intestine or 5-HT in the area postrema (Table 4). Treatment with standard metoclopramide (MCP; $30 \mathrm{mg} / \mathrm{kg})$ significantly decreased the upsurge of DA in the area postrema $(P<0.001)$ and brain stem $(P<0.01$; Table 4$)$.

Both fractions of $B M$ i.e. methanolic (BM-MetFr; 10, 20 and $40 \mathrm{mg}$ ) and butanolic (BMButFr; 5, 10 and $20 \mathrm{mg}$ ) were found to be highly effective in reducing the DA concentration $(P<0.001)$ in the area postrema with respect to the cisplatin control. A similar effect was also seen in the brain stem but with variable statistical significance $(P<0.05-0.001$; Table 4 5). However, BM-MetFr (20 and $40 \mathrm{mg} / \mathrm{kg}$ ) failed to attenuate DA concentrations in the brain stem (Table 4). Moreover, in the small intestine, there was a significant reduction $(P<0.001)$ in the levels of 5-HT in response to the $B M$ methanolic and butanolic fractions to all the doses tested, with the exception of BM-MetFr $(40 \mathrm{mg} / \mathrm{kg})$ and BM-ButFr $(5.0 \mathrm{mg} / \mathrm{kg})$. Furthermore, BM-MetFr $(40 \mathrm{mg} / \mathrm{kg})$ and BM-ButFr $(20 \mathrm{mg} / \mathrm{kg})$ significantly $(P<0.05)$ decreased the level of 5-HIAA in the area postrema (Table 4). 
Table 4 Effect of standard metoclopramide (MCP), $B M$ methanolic fraction (BM-MetFr) or n-butanolic fraction (BM-ButFr) on neurotransmitters (ng/mg tissue wet weight) and their metabolites in brain areas and the small intestine at 18 hours after cisplatin treatment in pigeons:

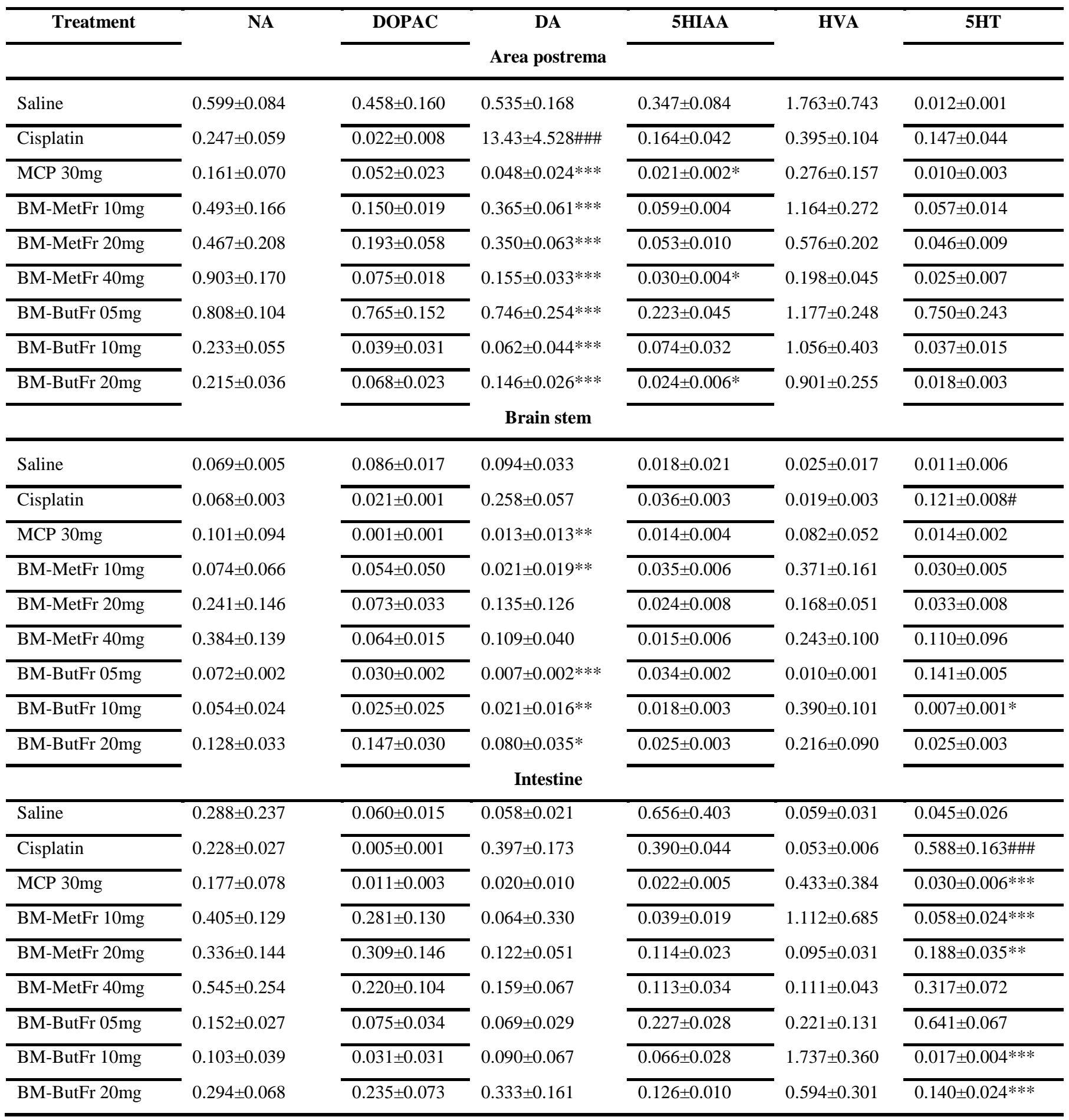


Neurotransmitter and metabolites values significantly different from cisplatin control are denoted by $* P<0.05 * * P<0.01 * * * P<0.001$, while values significantly different from basal level are indicated by \#P $<0.05 \# \# \# P<0.001$ (ANOVA followed by Tukey post hoc analysis; $n=6-8)$.

\section{Discussion:}

The pigeon is a species that has been used in emesis research for many years and it responds to a number of different emetic stimuli including cardiac glycosides $[45,46])$, reserpine [47], sigma receptor ligands [48], and the chemotherapeutic drugs cyclophosphamide [49] and cisplatin [50,51]. In terms of its translational value, it can be used to assay the antiemetic activity of several classes of drug including $5-\mathrm{HT}_{3}$ and $\mathrm{NK}_{1}$ receptor antagonists [16,52] and the glucocorticoids [53]. Investigators have studied lower doses of cisplatin $(4.0 \mathrm{mg} / \mathrm{kg})$, where the emetic response can continue for several days and is mediated by vagal and reserpine-sensitive monoaminergic systems $[16,54]$. In our studies, we used cisplatin at a dose of $7.0 \mathrm{mg} / \mathrm{kg}$ and found a reproducible emetic response in all animals for 24 hours without lethality. We also observed that cisplatin at the lower dose of $5.0 \mathrm{mg} / \mathrm{kg}$ induced vomiting in $60 \%$ of the animals and this slightly higher dose response relationship with respect to previous studies may be attributed to species differences, environmental factors and food. There is no mechanistically distinct acute or delayed phase of chemotherapy induced vomiting in the pigeon, even though previous studies have monitored emesis for up to 72 hours [16,53]. In our studies, we observed the animals for 24 hours to comply with the ethical use of animals.

Our study is the first to report the antiemetic activity of $B M$ in the pigeon model and this indicates that the antiemetic activity should be evaluated in other animal models such as the dog [55] and ferret [56] where delayed emesis can be observed. The major finding of 
the present study was that both methanolic and n-butanolic extracts of $B M$ possessed antiemetic activity with an efficacy and duration of action superior (MCP). MCP, a D2 and $5-\mathrm{HT}_{3}$ receptor antagonist with $5-\mathrm{HT}_{4}$ receptor agonist properties, was chosen as the reference standard drug [57]. The dose of MCP that we selected was higher than that required to antagonize cisplatin-induced emesis in other species [58], and was based on a previous study in the pigeon showing activity against reserpine induced emesis [59].

The anti-emetic activity of BM-MetFr prompted the screening of the bacoside rich nbutanolic fraction (BM-ButFr), which proved to be more potent than BM-MetFr indicating a potential inhibitory role of bacosides against vomiting induced by cisplatin. Bacosides have been reported to exhibit anticancer effects [60], potent antioxidant activity [37], and neuroprotective properties against aluminum induced oxidative stress $[38,39]$. Furthermore, there is a close mechanistic resemblance between the oxidative stress induced by aluminium and cisplatin in the cellular cytoplasm and mitochondria $[38,41]$. In the long term, $B M$ can restore the normal antioxidant defense mechanism of the body [61], which may be useful in protection against delayed emesis. It is possible that this action could further contribute to its antiemetic mechanism of action, since the antioxidant MPG is effective against cisplatin induced vomiting in the pigeon and this finding has also been reported in other species $[10,13]$. Nevertheless, the efficacious and potent antiemetic nature of $\mathrm{BM}-\mathrm{ButFr}$, compared to $\mathrm{MCP}$, may be putatively attributed to the bacoside $\mathrm{A}$ components namely bacoside $\mathrm{A}_{3}$, bacoside II and bacosaponin $\mathrm{C}$ which are detectable in the plant extract (n-butanolic fraction) in concentrations up to $57.91 \pm$ $3.2 \mu \mathrm{g} / \mathrm{mg}, 40.60 \pm 0.9 \mu \mathrm{g} / \mathrm{mg}$, and $17.23 \pm 1.7 \mu \mathrm{g} / \mathrm{mg}$, respectively. Likewise the three major components of bacoside $\mathrm{A}$ at a total concentration of $115.74 \pm 3.9 \mu \mathrm{g} / \mathrm{mg}$ were identified in BM-ButFr or $38.37 \pm 0.7 \mu \mathrm{g} / \mathrm{gm}$ of the dry powder, which concurs with an earlier report [44]. The presence of steroidal saponins, including bacoside A, which along 
with bacopaside 1 constituted more than $96 \%$ w/w of the total saponins of B. monniera [62], are able to cross the blood brain barrier and modulate enzyme activities, proteins, and neurotransmitters in different brain regions [63-67].

Treatment with $B M$ extracts decreased the concentration of 5-HT in the brain stem and intestine (Table 3) three hours following cisplatin administration. The $B M$ herb itself has been proved to be antioxidant [68] and this is one of the probable mechanisms by which BM-MetFr and BM-ButFr reduced the intestinal and brain stem concentration of 5-HT in comparison with MCP (Table 3). Thus, the decrease in 5-HT concentration may arise via protection of enterochromaffin (EC) cells from cisplatin-induced oxidative damage at the intestinal level, and this is an important consideration because $95 \%$ of $5-\mathrm{HT}$ is present in the EC cells of the gastrointestinal mucosa [31]. The decreases in 5-HT induced by both BM-MetFr and BM-ButFr in the brain stem and intestine are highly relevant to antiemetic propensity. In this context, EC cell 5 -HT release can subsequently stimulate $5-\mathrm{HT}_{3}$ receptors on vagal afferent fibres triggering an emetogenic 5-HT increase in the area postrema [69] and conversely, a 5-HT level decrement would be antiemetic.

Furthermore, there is evidence of a comparatively high density of 5- $\mathrm{HT}_{3}$ receptors in the NTS [70,71] and DMV [72] which would support the contention that $B M$ administration would be antiemetic.

$B M$ treatment had no effect on the levels of neurotransmitters (NA, DA and 5-HT) or their metabolites (DOPAC, HVA and 5-HIAA) in the area postrema during acute time (3 hour after cisplatin administration). However, the area postrema is thought to be involved in the delayed phase of vomiting because ablation of this medullary region suppresses it [73]. Furthermore, in the brain vomiting circuitry, dopamine receptors also located in the area postrema are regarded as the source of both morphine and apomorphine emesis [74- 
76]. Conversely, 5-HT is reported to be the primary mediator of the acute cisplatin vomiting response via the NTS [56,77] so it is possible that $B M$ influences this acute phase.

Literature regarding the delayed phase of cisplatin induced vomiting is indicative of overlapping mechanisms involving the role of substance P and DA [78,79]. $B M$ has been shown to inhibit hyperactivity and dopamine receptor supersensitivity induced by morphine as well as apomorphine climbing behavior in rats [36,80] and comparable findings have also been reported by our laboratory [81]. In the present study, cisplatin treatment resulted in a significant increase $(\mathrm{p}<0.001)$ in DA concentration $18 \mathrm{~h}$ post administration in the area postrema and a statistically nonsignificant effect in the concentration of DA in the intestine (Table 4). The magnitude of DA upsurge at the level of the area postrema was far greater than in the intestine, as the area postrema is considered to be involved in delayed sickness [73] and is the source of vomiting induction by morphine and apomorphine via the dopaminergic system [74]. Tanihata et al. [54] also observed a slight increase in DA concentration induced by cisplatin $(4 \mathrm{mg} / \mathrm{kg})$ in the small intestine when compared to other treatments in pigeons. In another study on minks, Qian and others [82] demonstrated a statistically significant increase $(p<0.05)$ in DA concentration in the area postrema and ileum after cisplatin treatment $(7.5 \mathrm{mg} / \mathrm{kg}) . \mathrm{In}$ a study in the least shrew animal model, cisplatin $(10 \mathrm{mg} / \mathrm{kg})$ increased $(\mathrm{p}<0.05)$ the DA concentration during both phases of vomiting while duodenal DA levels were unaffected [83]. In contrast, BM-MetFr and BM-ButFr treatments decreased the dopamine upsurge in the area postrema and brain stem (Table 4). These findings provide evidence in favor of an antiemetic effectiveness of $B M$ extracts for prolonged protection against cisplatin emetogenesis which is contingent upon DA function. Such antidopaminergic activity of 
$B M$ extracts is entirely complementary to previously reported neurochemical studies from this laboratory [43]. Furthermore, the $B M$ - induced decrease in 5-HIAA and 5-HT levels in the area postrema and intestine $18 \mathrm{~h}$ after cisplatin treatment may well be the manifestation of additional mechanism(s) involved in the anti-emetic properties of the herbal extracts.

Both $B M$ extracts failed to alter basal levels of neurotransmitters or their metabolites in the brain stem with the exception of a fall in 5-HIAA. Consequently, it might be argued that such comparative selectivity of their neurochemical activity for the area postrema and small intestine is an indicator of prospective safety and tolerability. Apart from a possible application in emetogenic chemotherapy, $B M$ has other additional properties including antinociceptive activity $[84,85]$ and efficacy in acute stress or chronic unpredictable stress [64] both of which may be advantageous in patients undergoing cancer chemotherapy [86].

In conclusion, the present study has disclosed that $B M$ extracts provide a long lasting suppression of vomiting induced by cisplatin, whereby anti-serotonergic and antidopaminergic activities occur over early and late emetic phases in a continuum. Thus during the early phase, anti-serotonergic effects predominate while in the later phase there is an anti-dopaminergic aftermath. $\mathrm{BM}-\mathrm{BuFr}$, which is rich in bacoside $\mathrm{A}$, showed superior antiemetic activity, thus implicating the role of bacoside $\mathrm{A}$ in the antiemetic activity of $B M$, though further studies are required ti investigate the involvement of its individual components. Moreover, $B M$ is known to be non-addictive, and has a tolerable safety profile making it worthy of further investigation as an anti-emetic agent, or at least an adjunct, against cisplatin induced vomiting in other animal models as well as in man. 


\section{Materials and Methods:}

\section{Animals:}

Pigeons of either sex (mixed breed, Department of Pharmacy, University of Peshawar, Pakistan) weighing between 250 - 350g were used. They were housed in groups of eight at 22 - $26{ }^{\circ} \mathrm{C}$ under a $12 \mathrm{~h}: 12 \mathrm{~h}$ light/dark cycle and had free access to food (locally available food; millet + wheat) and water before and during experimentation. All the experimental procedures were approved by the Ethical Committee, Department of Pharmacy, University of Peshawar (Ref. No 5/pharm) and are in accordance with the UK animal scientific procedure Act, 1986.

\section{Drugs and chemicals:}

Cisplatin $(\geq 99.9 \%) \quad$ (Korea United Pharm. Inc. Korea), metoclopramide (MCP; GlaxoSmithKline Pakistan Ltd.), N-(2-Mercaptoprpionyl) glycine (MPG $\geq 98 \%$; Sigma Aldrich Germany), NA $\geq 98 \%$, DOPAC $\geq 98 \%$, DA $\geq 99 \%, 5$ HIAA $\geq 98 \%$, HVA $\geq 98 \%, 5-\mathrm{HT}$ $\geq 99 \%$ (Acros Organics, Belgium), HPLC grade acetonitrile (99.9\%), methanol (99.9\%) and 1-octane sulphonic acid sodium salt (>98\%) (Fisher scientific U.K), sodium dihydrogen orthophosphate sodium (99\%) and EDTA ( $\geq 99 \%$ ) (Merck), Bacoside $A_{3}(\geq 95 \%)$, Bacoside II ( $\geq 99 \%$ ) and Bacosaponin C ( $\geq 90 \%$ ) (a gift from Prof. Dr. Ikhlas Khan, the National Center for Natural Products Research, University of Mississippi USA), commercial grade methanol, n-hexane, n-butanol and acetone (Haq Chemicals Peshawar).

\section{Extraction of Bacopa monniera and fractionation:}

The plant was collected in November from Rumalee stream near Quaid-e-Azam University, Islamabad Pakistan. The plant was authenticated by Prof. Dr. Muhammad Ibrar, Department of Botany, University of Peshawar and a specimen was deposited in the herbarium (Voucher 
No 7421). The aerial parts were separated, shade dried and coarsely powdered. A $1 \mathrm{~kg}$ sample of the resultant plant material was extracted with $n$-hexane $(6 \mathrm{~L})$, and then with acetone $(5 \mathrm{~L})$ to remove fats and chlorophyll-type pigments. The product was then extracted using commercial grade methanol $(1.5 \mathrm{~L})$ in a soxhelet apparatus to yield $28 \mathrm{~g}$. The resultant material was subfractionated to obtain the $n$-butanol fraction (yield 1.6 grams), which is reported to be rich in bacosides [87]. The methanolic fraction (BM-MetFr) and the bacoside rich n-butanolic fraction (BM-ButFr) of the plant were dissolved in distilled water prior to antiemetic testing.

\section{Gross phytochemical investigation:}

$B M$ was screened preliminarily, for the presence of glycosides [88] namely triterpenoids [89], tannins , flavonoids , saponins [90] and alkaloids [89,91].

\section{Quantification of Bacosides in $B M$ methanol and n-butanol fractions:}

High performance liquid chromatography coupled with UV was used for the quantification of Bacoside "A" major components bacoside $\mathrm{A}_{3}$, bacoside II and bacosaponin $\mathrm{C}$ using our own method with slight modification [44]. Briefly, 5mg of BM-MetFr or BM-ButFr was dissolved in $5 \mathrm{~mL}$ of HPLC grade methanol, centrifuged at $3000 \mathrm{rpm}$ for 10 minutes and filtered through $0.45 \mu$ filter. $300 \mu \mathrm{L}$ of the filtered solution was further diluted with methanol to make up a volume of 5mL. HPLC system equipped with LC-20AT double pumps (Shimadzu, Japan), a rheodyne injector of $20 \mu \mathrm{L}$ loop, SPD-20A UV detector (PDA) and purospher C18 column $(250 \mathrm{~mm} \times 4.6 \mathrm{~mm} \times 4 \mu \mathrm{m}$ particle size $)$ was used. The mobile phase consisted of 0.2 $\%$ phosphoric acid and acetonitrile $(62: 38, \mathrm{v} / \mathrm{v})$. The mobile phase $\mathrm{PH}$ was adjusted to 3 using $3 \mathrm{M} \mathrm{NaOH}$. 


\section{Drug formulation:}

Cisplatin was dissolved in normal saline by heating up to $60^{\circ} \mathrm{C}$, cooled to $40-45^{\circ} \mathrm{C}$ and immediately administered. The methanolic and n-butanolic fractions of $B M$ were dissolved in normal saline by gentle agitation and sonicated to get a clear solution for in vivo administration.

\section{Drug administration:}

Cotton wool and methylated spirits were used to sterilize the skin prior to drug administration. Intravenous and intramuscular administrations were done through the brachial wing vein and chest muscle, respectively using Neoject $2 \mathrm{ml}$ non-pyrogenic syringes with sharp painless needles $(27 \mathrm{G} \times 1 / 2$ " for the i.v. route, and $23 \mathrm{G} \times 1$ " for the i.m. route). Immediately, after the last injection, the animals were put back in the specially designed confining/observation cages and the incident counts of $\mathrm{R}+\mathrm{V}$ and latency to first vomit were recorded for $24 \mathrm{~h}$. At the end of experiment, body weight loss was calculated. Subsequently, the animals were decapitated to terminate the experiment.

\section{Antiemetic assay:}

On the day of the experiment, the pigeons were placed in individual cages specially designed for video observation. A preliminary study was conducted to evaluate the optimal dose of cisplatin to induce vomiting. Thus, cisplatin $(2.0-10 \mathrm{mg} / \mathrm{kg})$ was administered intravenously via the brachial wing vein at 0 minutes $(t=0)$ [54]. The behavior of each pigeon was then recorded for 24 h. Food and water were available during the observation period and each animal was used only once. The response with or without oral expulsion was considered as one vomiting episode [92]. The latency to first vomit and the number of vomiting episodes were recorded. A vomiting episode was considered to be completed when the pigeon adopted relaxed posture. Jerking episodes, which are indicative of vomiting intensity, were 
also recorded. In subsequent antiemetic studies, cisplatin was used at $7.0 \mathrm{mg} / \mathrm{kg}$, i.v. to elicit an emetic response to enable assessment of the potential antiemetic action of the $B M$ fractions, MCP and MPG. In these studies, BM-MetFr, BM-ButFr, MCP and MPG or respective vehicles, were administered 30 minutes before cisplatin administration.

\section{Tissue sampling for neurotransmitters analysis:}

Two discrete parts of the brain (brain stem and area postrema) as well as the intestinal samples $5-6 \mathrm{~cm}$ from the pylorus were used for the neurotransmitter analyses and the effects of BM-MetFr, BM-ButFr and MCP were investigated. At the end of each experiment, animals were decapitated and the brain areas and intestinal samples were rapidly dissected and placed on an ice cold plate $\left(0^{\circ} \mathrm{C}\right)$. The dissection of brain parts was carried out according to the atlas of Karten and Hodos [93] and Henri M. Duvernoy [94]. After decapitation of experimental animals, the dorsal surface of the skull was exposed by making an incision along the midline, and the temporal muscles were stripped off to expose the skull bone. After exposing the skull, bones and meninges were carefully removed in such a way to expose the brain hemispheres, especially to make the brain stem prominent from the ventral aspect. The long strip of capillaries stretching from the obex on the median line to the lateral angles of the fourth ventricle (area postrema) was dissected followed by dissection of the brain stem. Jejunal samples of about $2 \mathrm{~cm}$ were rapidly removed and washed with ice cold saline. The collected samples were rapidly frozen on an ice plate and stored at $-80^{\circ} \mathrm{C}$ until analysis.

\section{Determination of neurotransmitters and their metabolites:}

Tissue samples were homogenized in cold $0.2 \%$ perchloric acid (PCA) at $5000 \mathrm{rpm}$ with the help of Teflon glass homogenizer (Wise stir HS 30 E). After centrifugation (Centurion UK) at $12000 \mathrm{~g} / \mathrm{min}\left(4^{\circ} \mathrm{C}\right)$ the samples were filtered through a 0.45 micron filter. Neurotransmitters and their metabolites were analyzed using a high performance liquid 
chromatography system (HPLC, Shimadzu, Japan) coupled with electrochemical detection (ECD, ESA Coulochem III model 5300), a pump (model LC-20AT), and an analytical column (Teknokroma 3 x 150, 3um). The mobile phase consisted of $94 \mathrm{mM}$ sodium dihydrogen orthophosphate, $40 \mathrm{mM}$ Citric acid, $2.3 \mathrm{mM}$ sodium 1-octane sulphonic acid, 50 uM EDTA, and $10 \%$ acetonitrile $(\mathrm{pH} \mathrm{3})$. The flow rate was maintained at $0.6 \mathrm{~mL} / \mathrm{min}$. The standards used were NA hydrochloride, DOPAC, DA hydrochloride, 5HIAA, HVA and 5HT. The HPLC method was reproducible and all the neurotransmitters and their metabolites were separated within 13 minutes.

\section{Statistical analysis:}

The differences between means were evaluated using a one way analysis of variance (ANOVA) followed by Tukey's multiple comparison tests. $\mathrm{P}<0.05$ was considered as statistically significant. The animals which showed complete suppression of $\mathrm{R}+\mathrm{V}$ were not included in statistical analyses for latency. Data represent the mean \pm SEM unless otherwise indicated.

\section{Supporting information}

The structures of the major bioactive components of bacoside $\mathrm{A}$ and details of the phytochemical screening of BM-MetFr are available as Supporting Information

\section{Acknowledgments:}

We sincerely thank Higher Education Commission of Pakistan for sponsoring the studies. We are thankful to Korea United Pharm.Inc Korea for donating cisplatin active material for this study. We are also thankful to Professor Dr. Ikhlas A. Khan, the National Center for Natural Products Research, Mississippi, USA for the gift of HPLC standards of Bacosides. 


\title{
Conflict of Interest
}

The authors have no conflicts of interest to declare.

\author{
Affiliations \\ ${ }^{1}$ Department of Pharmacy, University of Swabi, Swabi, Pakistan \\ ${ }^{2}$ Department of Pharmacy, University of Peshawar, Peshawar, Pakistan \\ ${ }^{3}$ School of Biomedical Sciences, Faculty of Medicine, The Chinese University of Hong \\ Kong, Shatin, N.T., Hong Kong SAR, China \\ ${ }^{4}$ Department of Pharmacy, COMSATS Institute of Information Technology, \\ Abbottabad, Pakistan \\ ${ }^{5}$ Welsh School of Pharmacy, Cardiff University, Cardiff, UK
}

\section{References}

1 Topal A, Kaya M, Gül N. Ondansetron and granisetron in prophylaxis of nausea and emesis induced by cisplatin in dogs. Acta Vet Brno 2005;74: 111-116

2 Glaus A, Knipping C, Morant R, Böhme C, Lebert B, Beldermann F, Glawogger B, Ortega PF, Hüsler A, Deuson R. Chemotherapy-induced nausea and vomiting in routine practice: a European perspective. Support Care Cancer 2004; 12: 708-715

3 Naylor R, Rudd J. Mechanisms of chemotherapy/radiotherapy-induced emesis in animal models. Oncology 1996; 53: 8-17

4 Sharma S, Kochupillai V, Gupta S, Seth S, Gupta Y. Antiemetic efficacy of ginger (Zingiber officinale) against cisplatin-induced emesis in dogs. J Ethnopharmacol 1997; 57: 93-96

5 Cubeddu L. Mechanisms by which cancer chemotherapeutic drugs induce emesis. Semin Oncol 1992; 19: 2-13

6 Rossel R, Moreno I, Abed A. Delayed emesis after cisplatin treatment: incidence, source and management. In: Diaz-Rubio E, Martin M, editors. Antiemetic therapy: current status and future prospects. Madrid:Creaciones Elba, SA; 1992: 202-209 
7 Molassiotis A, Brearley SG, Stamataki Z. Use of antiemetics in the management of chemotherapy-related nausea and vomiting in current UK practice. Support Care Cancer 2011; 19: 949-956

8 Sodhi A, Gupta P. Increased release of hydrogen peroxide (H2O2) and superoxide anion $\left(\mathrm{O}_{2}^{-}\right)$by murine macrophages in vitro after cisplatin treatment. Int $\mathbf{J}$ Immunopharmacol 1985; 8: 709-714

9 Sangeetha P, Das U, Koratkar R, Suryaprabha P. Increase in free radical generation and lipid peroxidation following chemotherapy in patients with cancer. Free Radic Biol Med 1990; 8: 15-19

10 Torii Y, Mutoh M, Saito H, Matsuki N. Involvement of free radicals in cisplatin-induced emesis in Suncus murinus. Eur J Pharmacol 1993; 248:131-135

11 Matsuki N, Torii Y, Saito H. Effects of iron and deferoxamine on cisplatin-induced emesis: further evidence for the role of free radicals. Eur J Pharmacol 1993; 248: 329-331

12 Minami M, Endo T, Hirafuji M, Hamaue N, Liu Y, Hiroshige T, Nemoto M, Saito H, Yoshioka M. Pharmacological aspects of anticancer drug-induced emesis with emphasis on serotonin release and vagal nerve activity. Pharmacol Ther 2003; 99: 149-165

13 Gupta Y, Sharma S. Antiemetic activity of antioxidants against cisplatin-induced emesis in dogs. Environ Toxicol Pharmacol 1996; 1: 179-184

14 Lucot JB. Blockade of 5-hydroxytryptamine ${ }_{3}$ receptors prevents cisplatin-induced but not motion- or xylazine-induced emesis in the cat. Pharmacol Biochem Behav 1989; 32: 207-210 15 Yamakuni H, Nakayama H, Matsui S, Imazumi K, Matsuo M, Mutoh S. Inhibitory effect of zacopride on cisplatin-induced delayed emesis in ferrets. J Pharmacol Sci 2006; 101: 99102

16 Tanihata S, Oda S, Kakuta S, Uchiyama T. Antiemetic effect of a tachykinin NK1 receptor antagonist GR205171 on cisplatin-induced early and delayed emesis in the pigeon. Eur J Pharmacol 2003; 461: 197-206

17 Ray AP, Chebolu S, Darmani NA. Receptor-selective agonists induce emesis and Fos expression in the brain and enteric nervous system of the least shrew (Cryptotis parva). Pharmacol Biochem Behav 2009; 94: 211-218

18 Darmani NA, Johnson JC. Central and peripheral mechanisms contribute to the antiemetic actions of delta-9-tetrahydrocannabinol against 5-hydroxytryptophan-induced emesis. Eur $\mathbf{J}$ Pharmacol 2004; 488: 201-212

19 Darmani $N$, Zhao $W$, Ahmad $B$. The role of $D_{2}$ and $D_{3}$ dopamine receptors in the mediation of emesis in Cryptotis parva (the least shrew). J Neural Transm 1999; 106: 10451061

20 Darmani NA, Crim JL. Delta-9-tetrahydrocannabinol differentially suppresses emesis versus enhanced locomotor activity produced by chemically diverse dopamine $D_{2} / D_{3}$ receptor agonists in the least shrew (Cryptotis parva). Pharmacol Biochem Behav 2005; 80: 35-44 
21 Osinski MA, Uchic ME, Seifert T, Shaughnessy TK, Miller LN, Nakane M, Cox BF, Brioni JD, Moreland RB. Dopamine D2, but not D4, receptor agonists are emetogenic in ferrets. Pharmacol Biochem Behav 2005; 81:211-219

22 Saito R, Takano Y, Kamiya HO. Roles of substance P and NK1 receptor in the brainstem in the development of emesis. J Pharmacol Sci 2003; 91: 87-94

23 Le Moine C, Bloch B.D1and D2 dopamine receptor gene expression in the rat striatum: sensitive cRNA probes demonstrate prominent segregation of $\mathrm{D}_{1}$ and $\mathrm{D}_{2}$ mRNAs in distinct neuronal populations of the dorsal and ventral striatum. J Comp Neurol 1995; 355: 418-426

24 Higgins G, Kilpatrick G, Bunce K, Jones B, Tyers M. 5- $\mathrm{HT}_{3}$ receptor antagonists injected into the area postrema inhibit cisplatin-induced emesis in the ferret. Br J Pharmacol 1989; 97: $247-255$

25 Du Sert NP, Rudd J, Apfel C, Andrews P. Cisplatin-induced emesis: systematic review and meta-analysis of the ferret model and the effects of 5- $\mathrm{HT}_{3}$ receptor antagonists. Cancer Chemother Pharmacol 2011; 67: 667-686

26 Grélot L, Dapzol J, Estève E, Frugière A, Bianchi AL, Sheldrick RL, Gardner CJ, Ward P. Potent inhibition of both the acute and delayed emetic responses to cisplatin in piglets treated with GR205171, a novel highly selective tachykinin NK1 receptor antagonist. Br J Pharmacol 1998; 124: 1643-1650

27 Kim DY, Camilleri M. Serotonin: a mediator of the brain-gut connection. Am J Gastroenterol 2000; 95: 2698-2709

28 Minami M, Endo T, Hamaue N, Hirafuji M. Serotonin and anticancer drug-induced emesis. Yakugaku Zasshi 2004; 124: 491-507

29 Grunberg SM, Koeller JM. Palonosetron: a unique 5- $\mathrm{HT}_{3}$ receptor antagonist for the prevention of chemotherapy-induced emesis. Expert Opin Pharmacother 2003; 4: 2297-2303

30 Cubeddu L, O’Connor D, Hoffmann I, Parmer R. Plasma chromogranin A marks emesis and serotonin release associated with dacarbazine and nitrogen mustard but not with cyclophosphamide-based chemotherapies. Br J Cancer 1995; 72: 1033-1038

31 Veyrat-Follet C, Farinotti R, Palmer JL. Physiology of chemotherapy-induced emesis and antiemetic therapy. Drugs 1997; 53: 206-234

32 Qureshi R, Bhatti G. Taxonomy of Scrophulariaceae from Nara desert, Pakistan. Pak J Bot 2008; 40: 973-978

33 Gohil KJ, Patel JA. A review on Bacopa monniera: Current research and future prospects. Int J Green Pharm 2010; 4: 1-9 
34 Russo A, Borrelli F. Bacopa monniera, a reputed nootropic plant: an overview. Phytomedicine 2005; 12: 305-317

35 Dar A, Channa S. Calcium antagonistic activity of Bacopa monniera on vascular and intestinal smooth muscles of rabbit and guinea-pig. J Ethnopharmacol 1999; 66: 167-174

36 Sumathi T, Veluchamy G. Inhibitory effect of Bacopa monniera on morphine induced pharmacological effects in mice. Nat Prod Sci 2007; 13: 46-53

37 Bhattacharya S, Bhattacharya A, Kumar A, Ghosal S. Antioxidant activity of Bacopa monniera in rat frontal cortex, striatum and hippocampus. Phytother Res 2000; 14: 174-179

38 Jyoti A, Sethi P, Sharma D. Bacopa monniera prevents from aluminium neurotoxicity in the cerebral cortex of rat brain. J Ethnopharmacol 2007; 111: 56-62

39 Jyoti A, Sharma D. Neuroprotective role of Bacopa monniera extract against aluminiuminduced oxidative stress in the hippocampus of rat brain. Neurotoxicology 2006; 27: 451-457

40 Kharbangar A, Khynriam D, Prasad S. Effect of cisplatin on mitochondrial protein, glutathione, and succinate dehydrogenase in Dalton lymphoma-bearing mice. Cell Biol Toxicol 2000; 16: 363-373

41 Santos N, Catao C, Martins N, Curti C, Bianchi M, Santos A. Cisplatin-induced nephrotoxicity is associated with oxidative stress, redox state unbalance, impairment of energetic metabolism and apoptosis in rat kidney mitochondria. Arch Toxicol 2007; 81: 495504

42 Deepak M, Sangli G, Arun P, Amit A. Quantitative determination of the major saponin mixture bacoside A in Bacopa monnieri by HPLC. Phytochem Anal 2005; 16: 24-29

43 Rauf K, Subhan F, Abbas M, Ul Haq I, Ali G, Ayaz M. Effect of acute and sub chronic use of Bacopa monnieri on dopamine and serotonin turnover in mice whole brain. Afr $\mathbf{J}$ Pharm Pharmacol 2012; 6: 2767-2774

44 Rauf K, Subhan F, Abbas M, Badshah A, Ullah I, Ullah S. Effect of bacopasides on acquisition and expression of morphine tolerance. Phytomedicine 2011; 18: 836-842

45 Hildebrand F, Paas E. Pharmacological studies on glycoside mixture from Boviea volubilis. Naunyn Schmiedebergs Arch Exp Pathol Pharmakol 1953; 220: 492-499

46 Hanzlik P, Wood D. The mechanism of digitalis-emesis in pigeons. J Pharmacol Exp Ther 1929; 37: 67-100

47 Gupta G, Dhawan B. Blockade of reserpine emesis in pigeons. Arch Int Pharmacodyn Ther 1960; 128: 481-490

48 Hudzik TJ. Sigma ligand-induced emesis in the pigeon. Pharmacol Biochem Behav 1992; 41: $215-217$ 
49 Wolff $\mathrm{MC}$, Leander JD. Effects of a 5-HT $\mathrm{HT}_{1 \mathrm{~A}}$ receptor agonist on acute and delayed cyclophosphamide-induced vomiting. Eur J Pharmacol 1997; 340: 217-220

50 Navarra P, Martire M, del Carmine R, Pozzoli G, Preziosi P. A dual effect of some $5-\mathrm{HT}_{3}$ receptor antagonists on cisplatin-induced emesis in the pigeon. Toxicol Lett 1992; 64: 745-749

51 Ullah I, Subhan F, Rauf K, Badshah A, Ali G. Role of gastrointestinal motility/gastric emptying in cisplatin-induced vomiting in pigeon. Afr J Pharm Pharmacol 2012; 6: 25922599

52 Wolff MC, Leander JD. Comparison of the antiemetic effects of a 5-HT $\mathrm{HA}_{1 \mathrm{~A}}$ agonist, LY228729, and 5- $\mathrm{HT}_{3}$ antagonists in the pigeon. Pharmacol Biochem Behav 1995; 52: 571575

53 Tanihata S, Oda S, Nakai S, Uchiyama T. Antiemetic effect of dexamethasone on cisplatin-induced early and delayed emesis in the pigeon. Eur J Pharmacol 2004; 484: 311321

54 Tanihata S, Igarashi H, Suzuki M, Uchiyama T. Cisplatin-induced early and delayed emesis in the pigeon. Br J Pharmacol 2000; 130: 132-138

55 Fukui H, Yamamoto M. Methotrexate produces delayed emesis in dogs: a potential model of delayed emesis induced by chemotherapy. Eur J Pharmacol 1999; 372: 261-267

56 Rudd J, Naylor R. Effects of 5-HT3 receptor antagonists on models of acute and delayed emesis induced by cisplatin in the ferret. Neuropharmacology 1994; 33: 1607-1608

57 Johnston KD, Lu Z, Rudd JA. Looking beyond 5-HT 3 receptors: a review of the wider role of serotonin in the pharmacology of nausea and vomiting. Eur J Pharmacol 2014; 722: 13-25

58 Zhang F, Wang L, Yang ZH, Liu ZT, Yue W. Value of mink vomit model in study of antiemetic drugs. World J Gastroenterol 2006; 12: 1300

59 Coronas R, Pitarch L, Mallol J. Blockade of reserpine emesis in pigeons by metoclopramide. Eur J Pharmacol 1975; 32: 380-382

60 D'Souza P, Deepak M, Rani P, Kadamboor S, Mathew A, Chandrashekar AP, Agarwal A. Brine shrimp lethality assay of Bacopa monnieri. Phytother Res 2002; 16: 197-198

61 Shinomol GK. Bacopa monnieri modulates endogenous cytoplasmic and mitochondrial oxidative markers in prepubertal mice brain. Phytomedicine 2011; 18: 317-326

62 Deepak M, Amit A. 'Bacoside B'- the need remains for establishing identity. Fitoterapia 2013; 87: 7-10

63 Singh H, Dhawan B. Neuropsychopharmacological effects of the Ayurvedic nootropic Bacopa monniera Linn. (Brahmi). Indian J Pharmacol 1997; 29: 359-365

64 Sheikh N, Ahmad A, Siripurapu KB, Kuchibhotla VK, Singh S, Palit G. Effect of 
Bacopa monniera on stress induced changes in plasma corticosterone and brain monoamines in rats. J Ethnopharmacol 2007; 111: 671-676

65 Das A, Shanker G, Nath C, Pal R, Singh S, Singh HK. A comparative study in rodents of standardized extracts of Bacopa monniera and Ginkgo biloba: anticholinesterase and cognitive enhancing activities. Pharmacol Biochem Behav 2002; 73: 893-900

66 Mathew J, Paul J, Nandhu M, Paulose C. Increased excitability and metabolism in pilocarpine induced epileptic rats: Effect of Bacopa monnieri. Fitoterapia 2010; 81: 546-551

67 Khan R, Krishnakumar A, Paulose C. Decreased glutamate receptor binding and NMDA $\mathrm{R} 1$ gene expression in hippocampus of pilocarpine-induced epileptic rats: neuroprotective role of Bacopa monnieri extract. Epilepsy Behav 2008; 12: 54-60

68 Ghosh T, Kumar Maity T, Das M, Bose A, Kumar Dash D. In vitro antioxidant and hepatoprotective activity of ethanolic extract of Bacopa monnieri Linn. aerial parts. Iran J Pharmacol Ther 2007; 6: 77-85

69 Minami M, Endo T, Nemoto M, Hamaue N, Hirafuji M, Monma Y, Yajima T, Yoshioka M, Saito H. How do toxic emetic stimuli cause 5-HT release in the gut and brain? In: aynold D, Andrews P, Davis CJ, editors. Serotonin and the scientific basis of anti-emetic therapy. Oxford: Oxford Clinical Communications; 1995: 68-76

70 Kwiatkowska M, Parker LA, Burton P, Mechoulam R. A comparative analysis of the potential of cannabinoids and ondansetron to suppress cisplatin-induced emesis in the Suncus murinus (house musk shrew). Psychopharmacology 2004; 174: 254-259

71 Himmi T, Perrin J, El Ouazzani T, Orsini JC. Neuronal responses to cannabinoid receptor ligands in the solitary tract nucleus. Eur J Pharmacol 1998; 359: 49-54

72 Laporte A, Koscielniak T, Ponchant M, Verge D, Hamon M, Gozlan H. Quantitative autoradiographic mapping of $5-\mathrm{HT}_{3}$ receptors in the rat CNS using $\left[{ }^{125} \mathrm{I}\right]$ iodo-zacopride and $\left[{ }^{3} \mathrm{H}\right]$ zacopride as radioligands. Synapse 1992; 10: 271-281

73 Percie du Sert N, Rudd JA, Moss R, Andrews PL. The delayed phase of cisplatin-induced emesis is mediated by the area postrema and not the abdominal visceral innervation in the ferret. Neurosci Lett 2009; 465: 16-20

74 Yoshikawa $\mathrm{T}$, Yoshida $\mathrm{N}$, Hosoki $\mathrm{K}$. Involvement of dopamine $\mathrm{D}_{3}$ receptors in the area postrema in R(+)-7-OH-DPAT-induced emesis in the ferret. Eur J Pharmacol 1996; 301: 143 $-149$

75 Miller AD, Leslie RA. The area postrema and vomiting. Front Neuroendocrinol 1994; 15: $301-320$

76 King GL. Animal models in the study of vomiting. Can J Physiol Pharmacol 1990; 68: 60-268

77 Nakayama H, Yamakuni H, Higaki M, Ishikawa H, Imazumi K, Matsuo M, Mutoh S. Antiemetic activity of $\mathrm{FK} 1052$, a 5- $\mathrm{HT}_{3}$ - and 5- $\mathrm{HT}_{4}$-receptor antagonist, in Suncus murinus 
and ferrets. J Pharmacol Sci 2005; 98: 396-403

78 Diemunsch P, Grélot L. Potential of substance P antagonists as antiemetics. Drugs 2000; 60: $533-546$

79 Darmani N, Janoyan J, Kumar N, Crim J. Behaviorally active doses of the $\mathrm{CB}_{1}$ receptor antagonist SR 141716A increase brain serotonin and dopamine levels and turnover. Pharmacol Biochem Behav 2003; 75: 777- 787

80 Rauf K, Subhan F, Abbas G, Ali G, Abid SMA, Arshad U, Sharif MJH. Bacopa Monnieri inhibits locomotor hyperactivity induced by morphine without altering noradrenaline. Pharmacologyonline 2013; 1: 172-181

81 Rauf K, Subhan F, Sewell RDE. A bacoside containing Bacopa monnieri extract reduces both morphine hyperactivity plus the elevated striatal dopamine and serotonin turnover. Phytother Res 2011; 26: 758-763

82 Qian QH, Yue W, Wang YX, Yang ZH, Liu ZT, Chen WH. Gingerol inhibits cisplatininduced vomiting by down regulating 5-hydroxytryptamine, dopamine and substance $\mathrm{P}$ expression in minks. Arch Pharm Res 2009; 32: 565-573

83 Darmani NA, Crim JL, Janoyan JJ, Abad J, Ramirez J. A re-evaluation of the neurotransmitter basis of chemotherapy-induced immediate and delayed vomiting: evidence from the least shrew. Brain Res 2009; 1248: 40-58

84 Vohora S, Khanna T, Athar M, Ahmad B. Analgesic activity of bacosine, a new triterpene isolated from Bacopa monnieri. Fitoterapia 1997; 68: 361-365

85 Subhan F, Abbas M, Rauf K, Arfan M, Sewell RDE, Ali G. The role of opiodergic mechanism in the activity of Bacopa monnieri extract against tonic and acute phasic pain modalities. Pharmacologyonline 2010; 3: 903-914

86 Charmandari E, Tsigos C, Chrousos G. Endocrinology of the stress response. Annu Rev Physiol 2005; 67: 259-284

87 Kahol AP, Singh T, Tandon S, Gupta MM, Khanuja SPS. Process for the preparation of an extract rich in bacosides from the herb Bacopa monnieri. US Patent 6833143 B; 2004

88 Okunlola A, Adewoyin BA, Odeku OA. Evaluation of pharmaceutical and microbial qualities of some herbal medicinal products in south western Nigeria. Trop J Pharm Res 2007; 6: 661-670

89 Nayak B, Pereira LMP. Catharanthus roseus flower extract has wound healing activity in Sprague Dawley rats. BMC Complement Altern Med 2006; 6: 41

90 Sofowora A. Research on medicinal plants and traditional medicine in Africa. J Altern Complem Med 1996; 2: 365-372

91 Oyedapo O, Sab F, Olagunju J. Bioactivity of fresh leaves of Lantana camara. Biomed Lett 1999; 59: 175-183 
92 Preziosi P, D’Amato M, Del Carmine R, Martire M, Pozzoli G, Navarra P.

The effects of 5- $\mathrm{HT}_{3}$ receptor antagonists on cisplatin-induced emesis in the pigeon. Eur $\mathrm{J}$ Pharmacol 1992; 221: 343-350

93 Karten HJ, Hodos W. A stereotaxic atlas of the brain of the pigeon: Columba livia. Baltimore: Johns Hopkins University Press; 1967

94 Duvernoy HM, Risold PY. The circumventricular organs: an atlas of comparative anatomy and vascularization. Brain Res Rev 2007; 56: 119- 147 